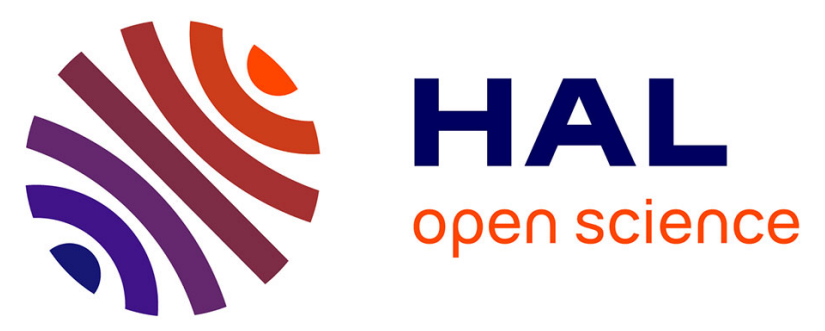

\title{
Click chemistry: an efficient tool to control the functionalization of metallic surfaces with alkyl chains possessing two reactive end groups
}

Damien Brunel, Vikas Jangid, Esteban Sanchez Adaime, David Duché, Anil Kumar Bharwal, Mathieu Abel, Mathieu Koudia, Thierry Buffeteau, Chrystelle Lebouin, Jean Jacques Simon, et al.

\section{To cite this version:}

Damien Brunel, Vikas Jangid, Esteban Sanchez Adaime, David Duché, Anil Kumar Bharwal, et al.. Click chemistry: an efficient tool to control the functionalization of metallic surfaces with alkyl chains possessing two reactive end groups. Applied Surface Science, In press, pp.150731. 10.1016/j.apsusc.2021.150731 . hal-03300612

\section{HAL Id: hal-03300612 \\ https://hal.science/hal-03300612}

Submitted on 27 Jul 2021

HAL is a multi-disciplinary open access archive for the deposit and dissemination of scientific research documents, whether they are published or not. The documents may come from teaching and research institutions in France or abroad, or from public or private research centers.
L'archive ouverte pluridisciplinaire HAL, est destinée au dépôt et à la diffusion de documents scientifiques de niveau recherche, publiés ou non, émanant des établissements d'enseignement et de recherche français ou étrangers, des laboratoires publics ou privés. 


\title{
Click chemistry: an efficient tool to control the functionalization of metallic surfaces with alkyl chains possessing two reactive end groups
}

\author{
Damien Brunel, ${ }^{1}$ Vikas Jangid, ${ }^{2,3}$ Esteban Sanchez Adaime, ${ }^{2}$ David Duché, ${ }^{2}$ Anil Kumar \\ Bharwal, ${ }^{2}$ Mathieu Abel, ${ }^{2}$ Mathieu Koudia, ${ }^{2}$ Thierry Buffeteau, ${ }^{4}$ Chrystelle Lebouin, ${ }^{3}$ \\ Jean Jacques Simon, ${ }^{2}$ Rose Marie Sauvage, ${ }^{5}$ Gerard Berginc, ${ }^{6}$ Ludovic Escoubas, ${ }^{2}$ \\ Didier Gigmes, ${ }^{1}$ Frédéric Dumur ${ }^{1}$ \\ ${ }^{1}$ Aix Marseille Univ, CNRS, Institut de Chimie Radicalaire ICR, UMR 7273, F-13397 \\ Marseille, France \\ ${ }^{2}$ Aix Marseille Univ, CNRS, Institut Nanomatériaux Microélectronique Nanosciences de \\ Provence IM2NP, UMR 7334, F-13397 Marseille, France \\ ${ }^{3}$ Aix Marseille Univ, CNRS, Matériaux Divisés, Interfaces, Réactivité, Electrochimie \\ MADIREL, UMR 7246, F-13397 Marseille, France \\ ${ }^{4}$ Univ. Bordeaux, Institut des Sciences Moléculaires ISM, CNRS UMR5255, F-33405 \\ Talence, France \\ ${ }^{5}$ DGA/AID, 75015, Paris, France \\ ${ }^{6}$ Thales Optronics, 78990, Elancourt, France
}

\begin{abstract}
Major challenges in the design of devices based on self-assembled monolayers (SAMs) standing in sandwich between two electrodes rely in SAMs of high quality and to simultaneously self-assemble them between two different electrodes, especially in case of Metal-Molecule-Metal junction devices. In this study, we demonstrate the synthesis and the characterization of two ferrocene-based functional molecules with two active thiol/thiol-acetate anchoring groups which could be used to bind with two different electrodes. To control the orientation of the molecules at the surface of the bottom electrode, a Copper catalysed Alkyne Azide Cycloaddition (CuAAC) (click chemistry) approach is applied on ultra-smooth template stripped gold substrates. Self-assembly of the two molecules could be obtained in two consecutive steps enabling us to control the orientation and the regularity of the SAMs. Cyclic voltammetry results shows that the SAMs obtained by mean of the two-step procedure are of high quality with more than $60 \%$ of the gold surface covered by molecules. We further investigated the SAMs by PM-IRRAS, XPS, ellipsometry and contact angle measurements to investigate the presence of functional groups, individual elements and succession of the click reaction on surface.
\end{abstract}

Keywords :

Ferrocene; Click Chemistry; surface functionalization; PM-IRRAS; XPS

\section{Introduction}

Self-Assembled Monolayers (SAMs) are thin layers of molecules that spontaneously self-organize into highly ordered structures at the surface of substrates during the deposition process. ${ }^{[1],[2],[3]}$ Over the years, the degree of sophistication and the ever-improved control of the structuration at the molecular 
scale have allowed these structures to be used in many research fields such as biosensors, ${ }^{[4]}$ organic electronics ${ }^{[5]}$ protein binding ${ }^{[6]}$ or selective surface modification. ${ }^{[7]}$ SAMs are typically formed by organic entities comprising a head group (responsible of the binding to the metallic surface by mean of physical or chemical forces), a spacer which can be of various natures (alkane chains or polyphenyl groups) and a terminal group (also called functional group), which is not involved in the autonomous nano-structuration of the molecular entities but plays an essential role for further applications. Typically, for the post-functionalization of SAMs, molecular entities composing SAMs comprise a functional end-group not engaged in the linkage with the surface, and which can react with the desired molecules bearing the complementary functional group for coupling. Using this two-step procedure, a surface modification can be carried out, providing a unique opportunity to bring photophysical properties (mechanical, electrical, magnetic or redox properties) to surfaces which are devoid of any properties. In most of the cases, the desired property is provided by the organic entities which are used for the post-functionalization of the SAMs. When molecular entities self-assemble onto a metal surface and when these entities possess at both ends a functional group that can react with the surface, the possibility for each extremity to react with the surface drastically compromise the molecular orientation of the molecular entities. A disorder is introduced on the surface, especially when asymmetric molecular entities are used to functionalize the surface. A relevant example of this has been provided during the work done by Hamoudi and coworkers ${ }^{[8]}$ who evidenced all the difficulties to conveniently functionalize a surface with molecules bearing two reactive terminal groups. Notably, the possible bounding of the two terminal groups onto the surface but also the formation of multimolecules by disulfide bond formation also causing the formation of multilayered structures on top of the substrate was clearly evidenced.

This issue can be overcome if a two-step procedure is used to fabricate SAMs. In this work, we notably show that this concept can be used to build up a well-defined SAM of an organic entity bearing two anchoring groups attached at both sides with an electroactive group standing in the middle of the carbon chain and which gives us an excellent control over the orientation of the molecule and the position of the electroactive group with regards to the metal surface. Using this two-step approach, the two anchoring groups cannot compete anymore for surface functionalization. The formation of SAMs of good quality can thus be expected. However, to achieve this ambitious goal, the selected chemical reaction should have a high reaction yield so that the coupling between the two connecting groups should not constitute a limitation for the design and engineering of molecular based electronic junctions. ${ }^{[9]}$ The development of SAMs bearing at the top of the monolayer, anchoring groups that can be advantageously used for a second surface functionalization is not new and examples of this approach have notably been reported with peptides, nucleotides, small molecules-based supramolecular structures and polymers using metal and metal-free catalysts to perform the chemical reaction. ${ }^{[10-11]}$

The different key-steps of this ambitious goal are depicted in Figure 1. 

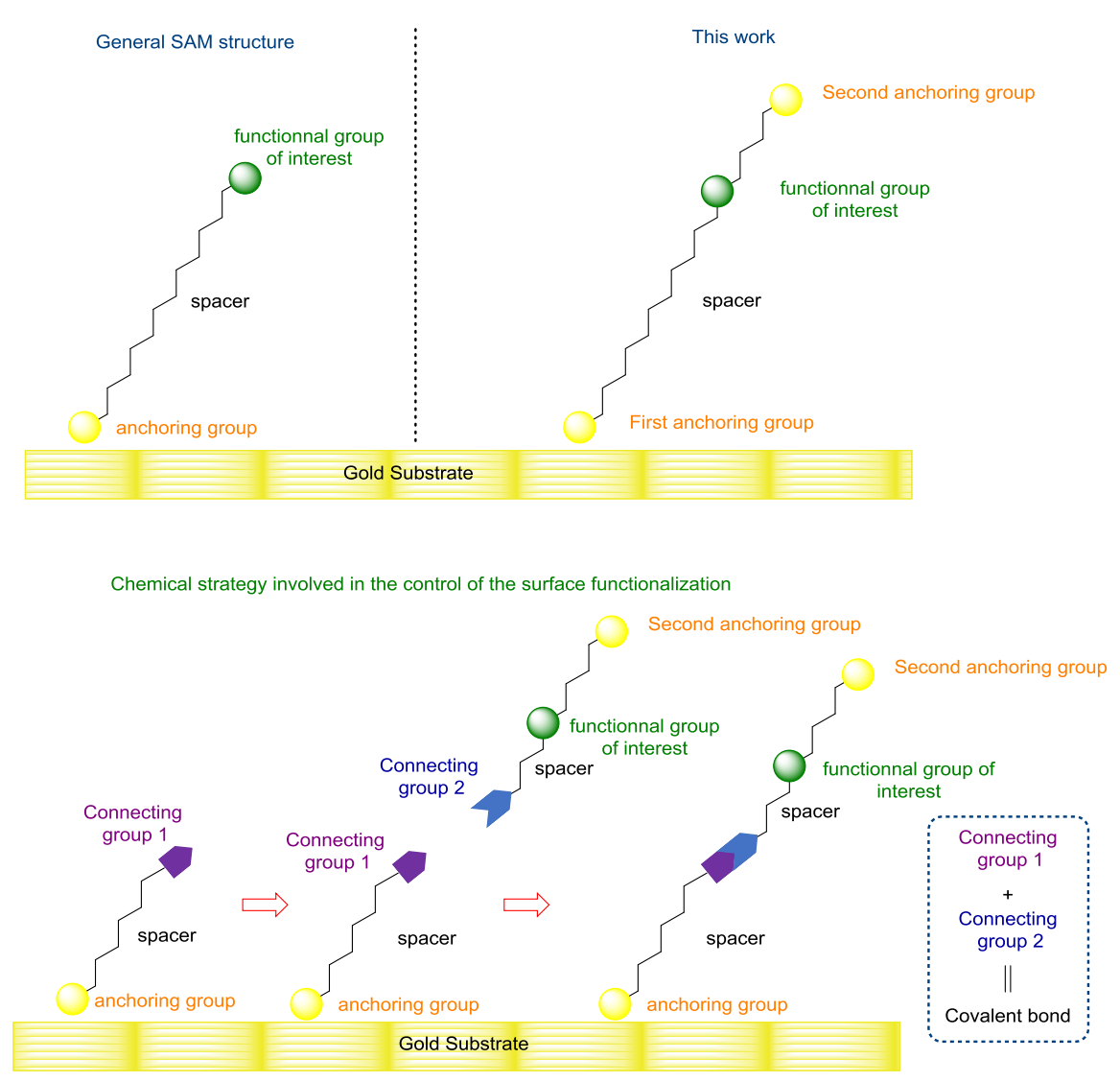

Figure 1: Left: General structure of SAM. Right: this work, describing SAM with two anchoring groups.

Among all chemical reactions reported in the literature, Copper catalysed Alkyne Azide Cycloaddition (CuAAC) reaction also named "click chemistry" has already been used to functionalize various metal surfaces due to its averred efficiency. ${ }^{[12]}$ Click chemistry is a very interesting approach for surface functionalization, as this chemical reaction can be carried out in mild conditions (at room temperature in non-hazardous solvents), while avoiding the presence of side reactions (since only the two connecting groups can react together and provides the reaction product in high yield without necessitating an extensive purification process). Due to these appealing features, CuAAc has been selected as the appropriate reaction for this work. It has to be noticed that surface modification by mean of click chemistry has already been investigated in the literature. Notably, Dadfar et al. has notably extensively studied thiol terminated surface modifications by comparing thiol-ene and thiolyne click reactions, ${ }^{[13]}$ deposition of protein microarray via thiol, amine and azide functionalities for biosensor applications, ${ }^{[14]}$ click reaction of alpha fetoprotein for immunosensing ${ }^{[15]}$ and catalyst free click reaction for biomedical and biological applications. ${ }^{[16]}$ The redox functional group selected in this study is ferrocene, which is extensively used for the formation of SAMs but also for its unique redox properties for various applications. ${ }^{[17]}$ For example, the reversible oxidation/reduction processes of ferrocene on surface allowed its use for the design of ions sensors, ${ }^{[18]}$ to trigger ion transfer across membranes. ${ }^{[19]}$ Lastly, ferrocene-containing compounds have also been extensively studied as molecular rectifiers, the best performances reported to date being obtained with these redox-active moieties. ${ }^{[20],[21],[22]}$ Additionally, click chemistry of ferrocene on surface is already documented in the literature, with a few examples reporting the successful surface modification. ${ }^{[23],[24],[25]}$

In this work, the unprecedented synthesis of two ferrocene derivatives Fc1 and Fc2 enabling to develop the stepwise functionalization of a gold surface is presented (see Figure 2). The synthesis of Fc1 and Fc2 is followed by joining the two entities, one with ferrocene moiety and other with carbon chain, each with click active functional group. The main difference between the two molecules is the 
presence of a carbon spacer between ferrocene and triazole in Fc1 and absent in Fc2 which arises because of the difference in click active functional groups in their respective precursors. The parallel to the synthesis of $\mathbf{F c 1}$ and $\mathbf{F c 2}$, formation of the corresponding SAMs as well as their photophysical characterizations are presented. Furthermore, to optimize the efficiency of the click reaction on gold surface, first part of the SAMs was prepared with octanethiol as a diluent for longer alkyl chains. Indeed, using this strategy, the terminal end-groups standing at the extremity of the chains are more accessible, optimizing the reaction yields. Considering the size of the ferrocene derivatives, only a small amount of azido or alkynyl chains are required for post-functionalization of the SAMs. Consequently, ferrocene-based SAMs were obtained by first depositing mixed SAMs (containing 19 or 20 and octanethiol as the diluent, figure 9) on top of the gold substrates and by subsequently functionalizing the resulting SAMs with the appropriate ferrocene derivatives i.e., $\mathbf{8}$ or $\mathbf{1 8}$ (see Figure 4 and 7).

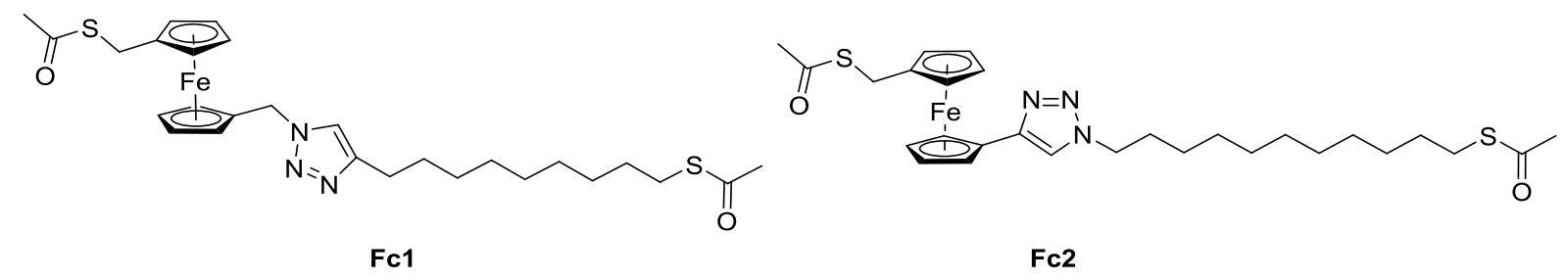

Figure 2: Chemical structures of the two organic entities used for the functionalization of gold surfaces.

\section{Synthesis}

\subsection{Synthesis of the molecule Fc1}

Synthesis of Fc1 could be realized in six steps starting from the commercially available undecyn-1-ol and ferrocene. First, undecyn-1-ol $\mathbf{1}$ could be converted into its thioacetate analogue $\mathbf{3}$ in high yield, following a procedure previously reported in the literature. ${ }^{[26]}$ The alcohol was activated as a mesylate intermediate $\mathbf{2}$, subsequently converted in $88 \%$ yield as a thioacetate derivative $\mathbf{3}$ using potassium thioacetate in methanol (See Figure 3).

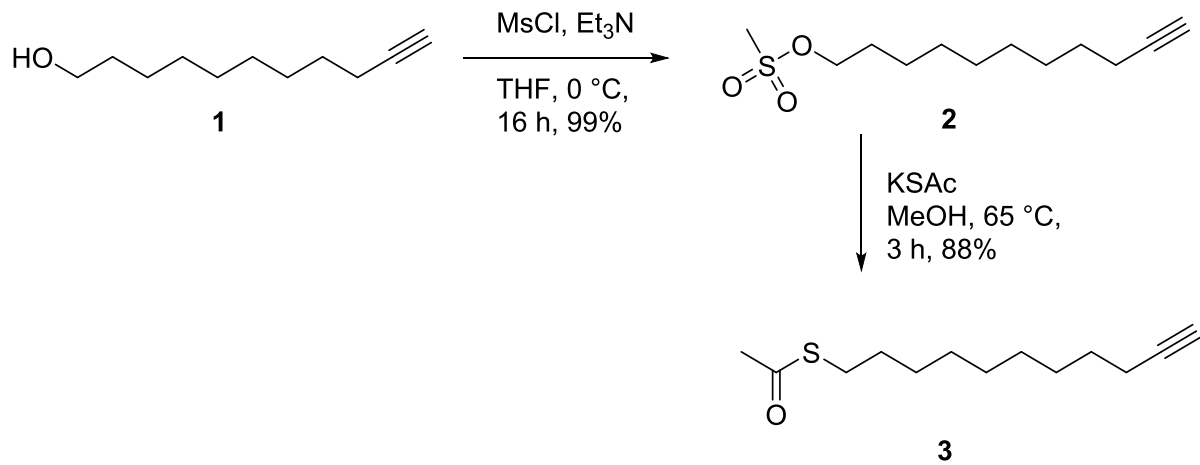

Figure 3: Synthetic route to 11-undecynyl-thioacetate.

Parallel to this, ferrocene 8 could be obtained in four steps starting from compound $\mathbf{4}$ (See Figure 4). After formation of the dialdehyde $\mathbf{5}$ by dilithiation of $\mathbf{4}$ with $n$-butyl lithium and subsequent treatment with $N, N$-dimethylformamide (DMF) ${ }^{[27]}$ this latter was reduced to alcohol $\mathbf{6}$ in high yield (90\%) using sodium borohydride in alcohol. ${ }^{[28]}$ Finally, 7 could be obtained by reaction of 6 with sodium azide in a biphasic reaction involving acidic water and ethyl acetate. ${ }^{[29]}$ The remarkable stability of the azide group in acidic conditions allowed the nucleophilic substitution of the alcohol in 7 with thioacetic acid under acidic catalysis (trifluoracetic acid), yielding 8 in $84 \%$. ${ }^{[30]}$ 
1) $n$-BuLi (2.2 equiv.), TMEDA

(2.2 equiv.), $\mathrm{Et}_{2} \mathrm{O}, 0{ }^{\circ} \mathrm{C}, 18 \mathrm{~h}$

2) $\mathrm{DMF}$ ( 2.2 equiv.), $\mathrm{Et}_{2} \mathrm{O},-70^{\circ} \mathrm{C}$,

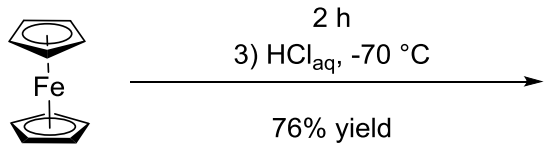

4

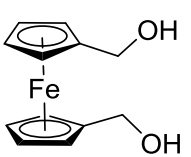

6

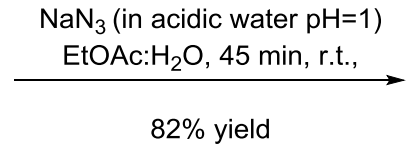

$82 \%$ yield

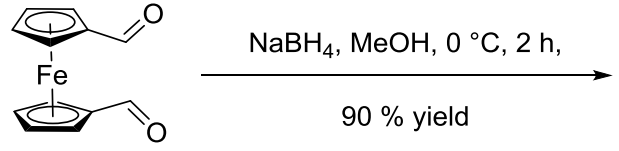

5

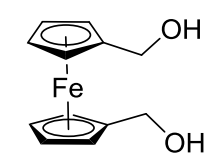

6

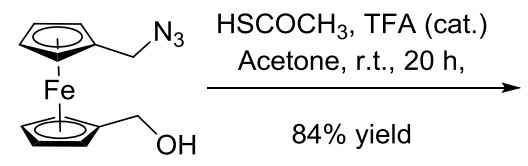

7

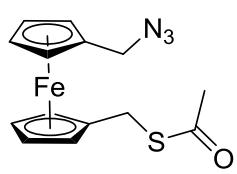

8

Figure 4: Four step synthesis of 8 starting from ferrocene 4.

Finally, the possibility to carry out a click reaction with $\mathbf{3}$ and $\mathbf{8}$ was first examined in classical solution-phase chemistry. The two parts $\mathbf{8}$ and $\mathbf{3}$ were engaged in reaction using the classical conditions of click chemistry (copper sulfate pentahydrate, sodium ascorbate in EtOH: water (1:1)), and the targeted compound Fc1 could be isolated in good yield (See Figure 5), demonstrating that the click reaction between $\mathbf{3}$ and $\mathbf{8}$ was possible in solution.
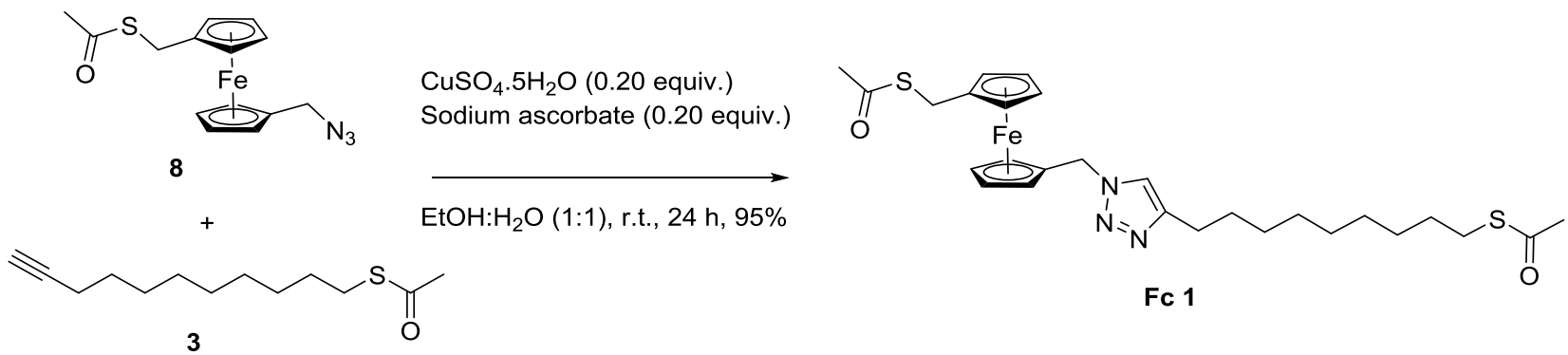

Figure 5: Click chemistry reaction of 8 and $\mathbf{3}$, giving $\mathbf{F c 1 .}$

\subsection{Synthesis of the molecule Fc2}

Concerning the synthesis of Fc2, the first task consisted in the synthesis of the alkyl chain in three steps, ${ }^{[31]}$ starting from 11-bromoundecanol 9. By nucleophilic attack of sodium azide on 9, alcohol $\mathbf{1 0}$ could be isolated in almost quantitative yield. Upon activation of the alcohol function with mesityl chloride, the elimination product $\mathbf{1 2}$ could be prepared from $\mathbf{1 1}$ in 50\% yield (See Figure 6).<smiles>OCCCCCCCCCCCBr</smiles>

9

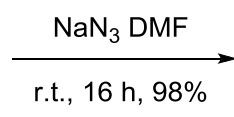<smiles>NCCCCCCCCCCCO</smiles>

10 $\mathrm{MsCl}, \mathrm{Et}_{3} \mathrm{~N}$
$\mathrm{THF}, 0^{\circ} \mathrm{C}, 16 \mathrm{~h}, 94 \%$<smiles>CC(=O)SCCCCCCCCCCCN=CC(C)(C)C(C)(C)C</smiles>

Figure 6: Synthetic pathway of the 11-azidoundecane thioacetate 12. 
The second ferrocene 18, used for the click reaction with 12 could be prepared in five steps, starting from the commercially available ferrocenecarboxyaldehyde 13. By a Friedel Crafts acylation, followed by a Vilsmeier Haack reaction and then basic treatment, 1-ethynyl-1'-formylferrocene 16 could be obtained in $71 \%$ yield. ${ }^{[32]}$ Then, reduction of the aldehyde group under mild reaction conditions followed by the nucleophilic substitution of alcohol $\mathbf{1 7}$ with thioacetic acid yielded $\mathbf{1 8}$ in $78 \%$ yield (See Figure 7).

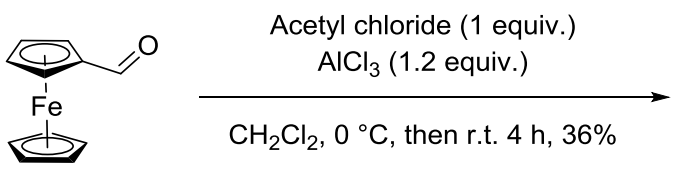

13

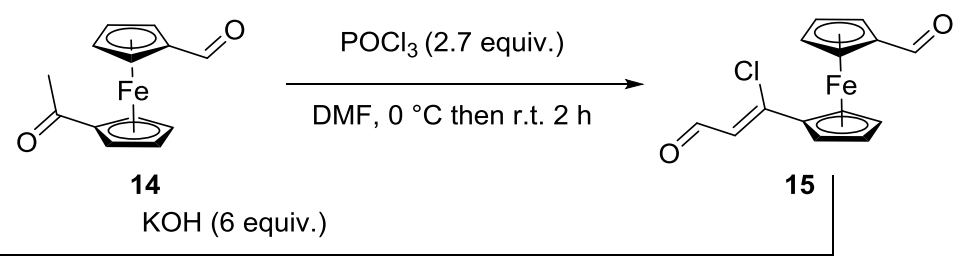

Water:Dioxane, $100^{\circ} \mathrm{C}, 10 \mathrm{~min}, 71 \%$

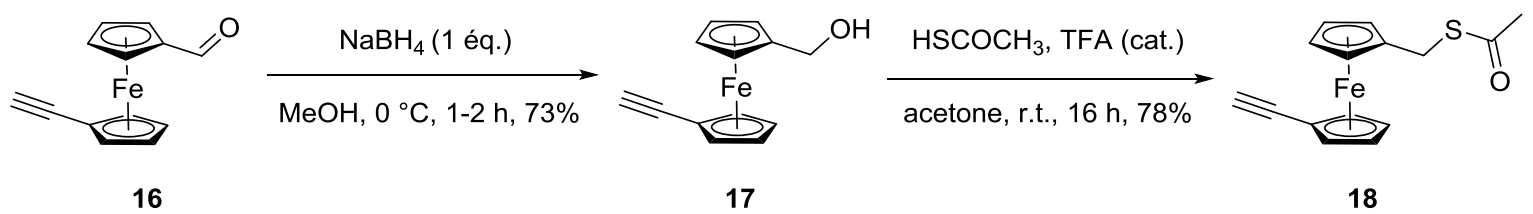

Figure 7: The five-step synthesis of 1-ethynyl-1'-thioacetylmethylferrocene 18.

Finally, the possibility to couple $\mathbf{1 8}$ and $\mathbf{1 2}$ by click chemistry was examined in solution and Fc2 could be isolated in $80 \%$ yield after $24 \mathrm{~h}$ of reaction (See Figure 8).

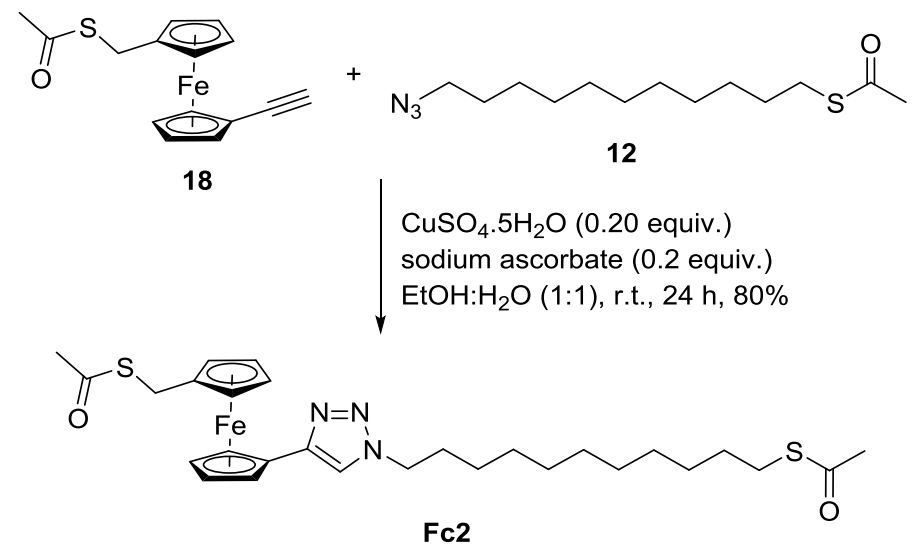

Figure 8: Click chemistry between 12 and $\mathbf{1 8}$, giving $\boldsymbol{F c 2}$.

\subsection{Synthesis of the different thiols}

Thiols are better candidates than their protected thioacetate analogues for SAMs elaboration. ${ }^{[33]}$ Notably, based on the literature, SAMs of higher quality can be obtained from thioalkyl chains than with thioacetyl chains. Indeed, in this last case, the protecting group can adversely affect the quality of the SAMs so that the use of free thiols is now clearly recommended. In this context, the long alkyl chains $\mathbf{1 2}$ and 3 were hydrolysed into their corresponding thiol analogues $\mathbf{1 9}$ and $\mathbf{2 0}$. The two alkanethiol chains were deprotected following procedures reported in the literature (See Figure 9). ${ }^{[26],[31]}$ 


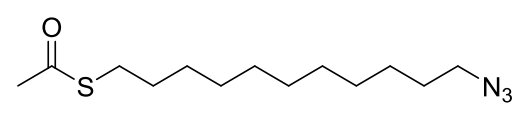

12

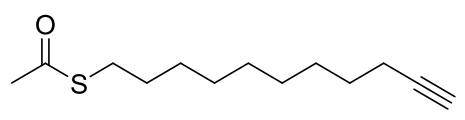

3
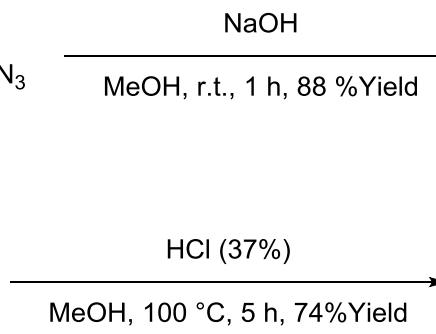

$\mathrm{MeOH}, 100^{\circ} \mathrm{C}, 5 \mathrm{~h}, 74 \%$ Yield

Figure 9: Deprotection of the two thioacetate alkyl chains 12 and 3.

\subsection{Formation of the SAMs}

Preparation of the SAMs was done in a two-step process. First, the substrate was immerged in a degassed ethanolic solution of a mixture of the reactive alkanethiol chain $(0.5 \mathrm{mM})$ and octanethiol $(0.5 \mathrm{mM})$ for $24 \mathrm{~h}$, at room temperature under argon. After rinsing the substrate, this latter was immerged in a degassed mixture of ethanol: water $(1: 1)$ containing $1 \mathrm{mM}$ of the ferrocenyl derivatives, $0.01 \mathrm{mM}$ of copper sulphate and $0.01 \mathrm{mM}$ of sodium ascorbate for $24 \mathrm{~h}$ at room temperature. Then, the substrate was rinsed with copious amount of water and ethanol and dried with argon. Following this protocol, four surfaces chemically modified were obtained as shown in the Figure 10: SAM 1 and SAM 3 associated with Fc1, SAM 2 and SAM 4 associated with Fc2. SAM 1 and SAM 3 will serve as indicator of reaction, by comparison with SAM 2 and SAM 4 characterizations. 


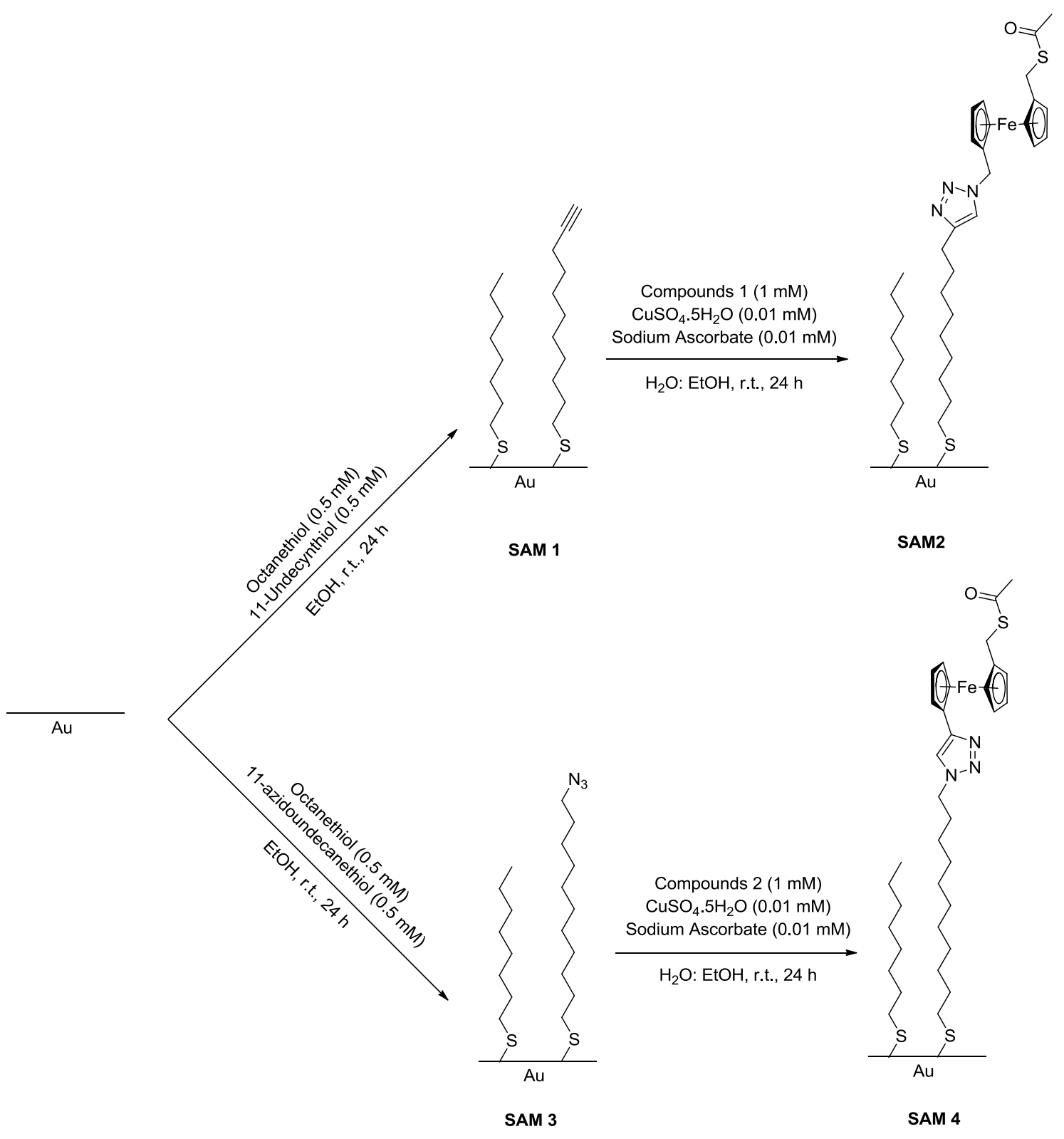

Figure 10: The experimental procedure used for SAM formation and the four SAM obtained.

\section{Characterization and results}

\subsection{Cyclic Voltammetry}

Cyclic voltammetry of the two SAMs chemically modified with ferrocenes clearly showed the presence of the redox centres on the gold surface. Effectively, for the SAM prepared with Fc1 (See Figure 11), the reversible oxidation peak obtained after click chemistry undoubtedly evidences the presence of ferrocene. The black curve corresponds to bare gold in the potential range of -0.1 to $0.9 \mathrm{~V}$ with respect to $\mathrm{Ag} / \mathrm{AgCl}$ reference electrode and $\mathrm{Pt}$ counter electrode, with no trace of any redox peak. After depositing the alkanethiol SAM 1, the red curve shows its characteristic by lowering the current density as it is an insulating film. And after click reaction a reversible oxidation-reduction peak appears in SAM 2, showing the presence of an electro-active species on the surface. Moreover, the value of $E_{1 / 2}(0.36 \mathrm{~V})$ is consistent with the oxidation potential of ferrocene, even in solution. ${ }^{[34]}$ 


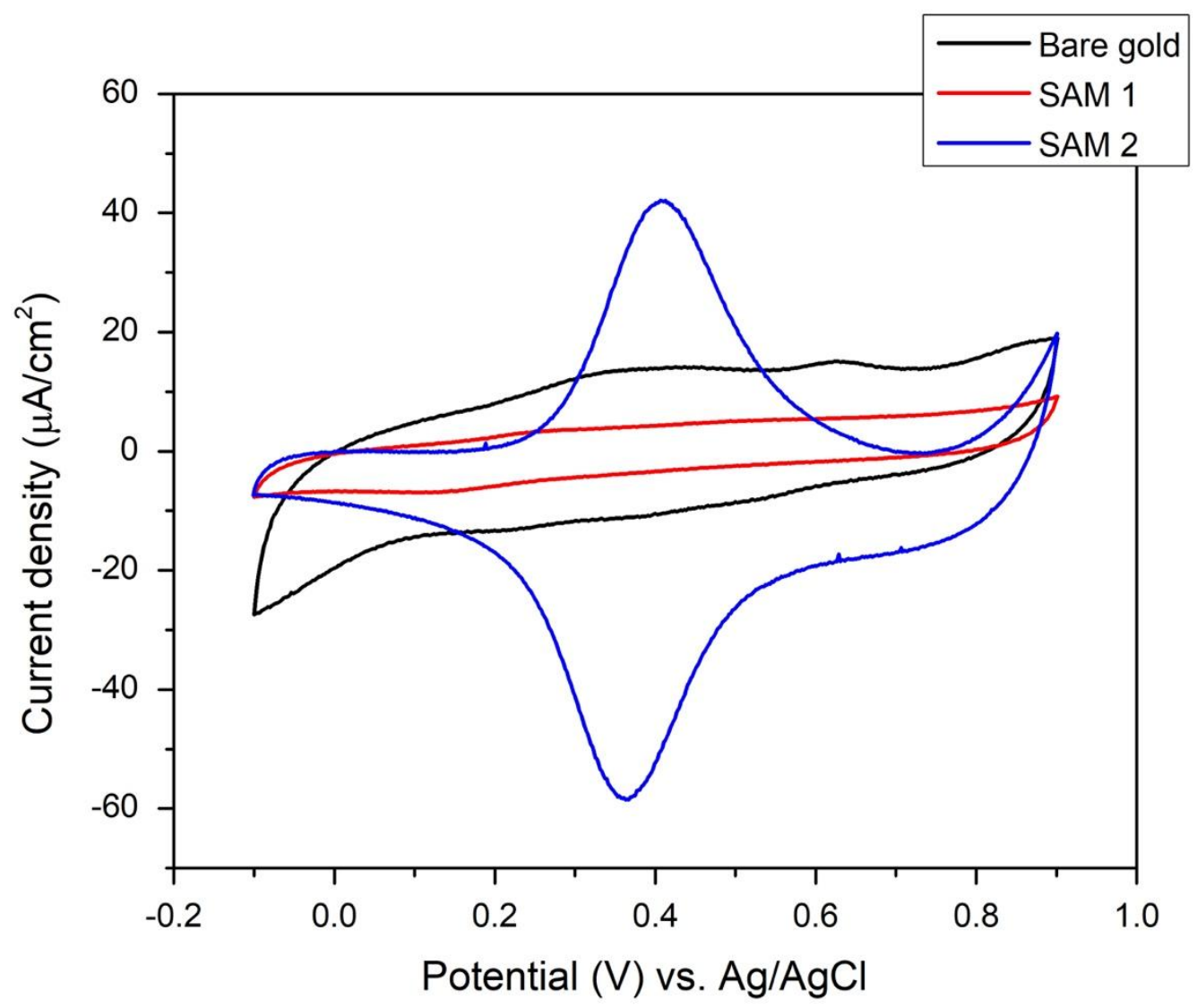

Figure 11: CV curve of before and after click chemistry on surface of Fc1 in $\mathrm{HClO}_{4}$ at $1 \mathrm{~V} / \mathrm{s}$ (black: Bare gold; red: SAM 1, blue: SAM 2).

Similarly, for the SAMs prepared with Fc2 i.e., SAM 3 and SAM 4, a reversible oxidationreduction peak was obtained on surface, showing here again the presence of ferrocene (se Figure 12). Moreover, the value of $\mathrm{E}_{1 / 2}$ (here $0.38 \mathrm{~V}$ ) is coherent with the presence of ferrocene.

The coverage of the above two surfaces with $\mathbf{F c 1}$ and $\mathbf{F c 2}$ also provides good information about the efficiency of the reaction on surface. The surface coverage, $\Gamma$, of SAM 2 and SAM 4 is calculated by integrating the oxidation and reduction peaks, considering the one electron oxidationreduction of ferrocene group, by the equation: $\Gamma=Q_{\mathrm{tot}} / 2 n F A$, where $Q_{\mathrm{tot}}$ is half of the total charge involved in one redox wave, $n$ is number of electrons transferred per molecule per redox cycle, $F$ is Faraday constant and $A$ is real surface area (here $0.5 \mathrm{~cm}^{2}$ ) of the gold electrode exposed to electrolyte solution. For the molecule Fc1, the surface coverage is $1.94 \times 10^{-10} \mathrm{~mol} / \mathrm{cm}^{2}$ for SAM 2, which is $43 \%$ of $4.5 \times 10^{-10} \mathrm{~mol} / \mathrm{cm}^{2}$, the theoretical value for full coverage of SAM of ferrocene-alkanethiol. ${ }^{[35]}$ For SAM 4, the surface coverage determined was of $2.92 \times 10^{-10} \mathrm{~mol} / \mathrm{cm}^{2}$ which is around $64.8 \%$. The reported value of click reaction on surface is $58 \%$ of the theoretical value due to incomplete yield of click reaction on surface and effect of diluent, which is in good agreement with our SAMs. ${ }^{[25],[35]}$ Hence, the click reaction on surface is better when the azide is on the surface and when the alkyne is in solution. These results are consistent with the literature. ${ }^{[36]}$ 


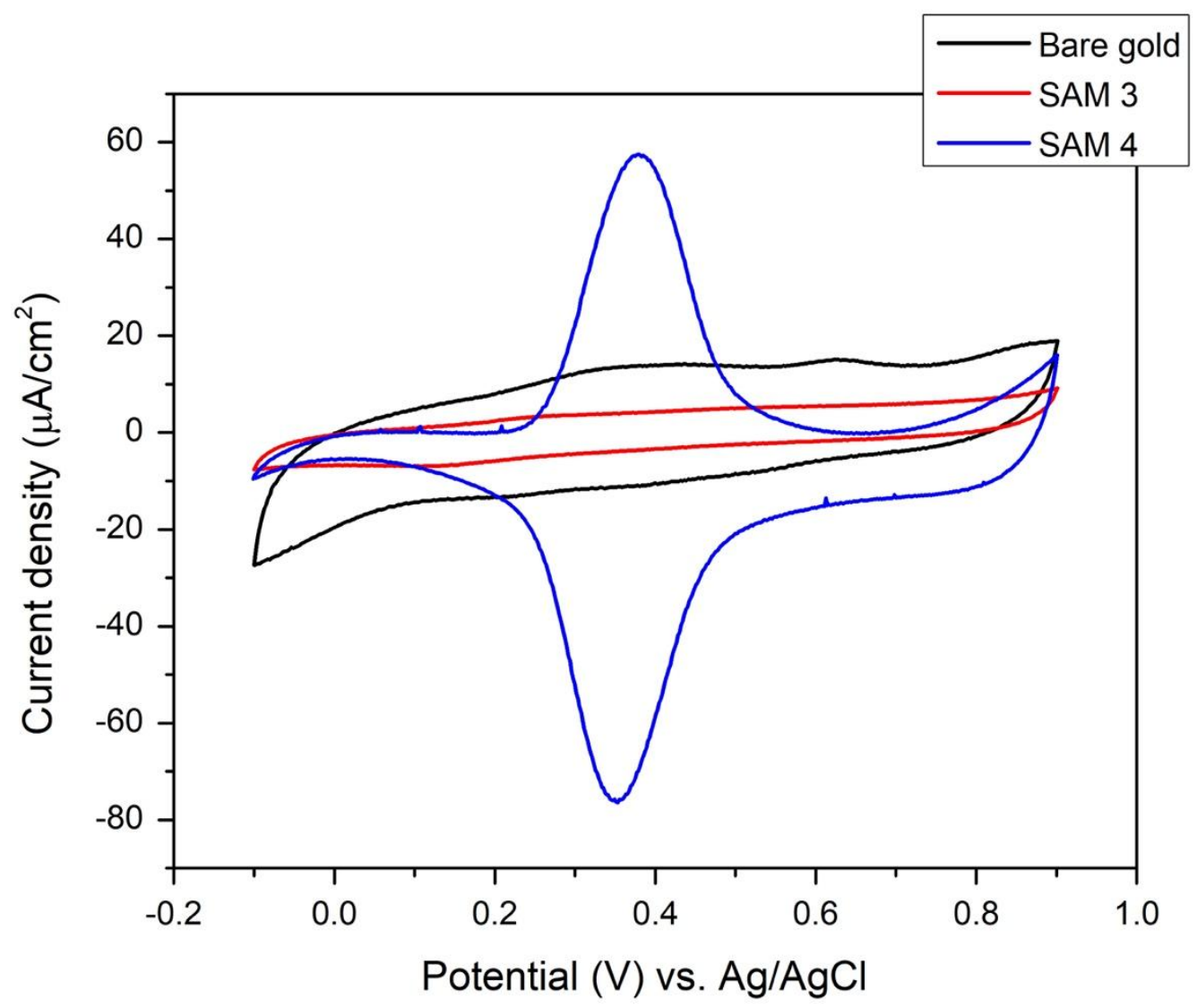

Figure 12: CV curve of before and after click chemistry on surface of Fc2 in $\mathrm{HClO}_{4}$ at $1 \mathrm{~V} / \mathrm{s}$ (black: Bare gold; red: $\mathbf{S A M ~ 3 ,}$ blue: SAM 4).

\subsection{PM-IRRAS}

A large number of techniques can be used to investigate and characterize SAMs, among which polarization modulation infrared reflection-absorption spectroscopy (PM-IRRAS) was selected as a method of choice to characterize the different monolayers. ${ }^{[37-40]}$ Additionally, this technique is a very simple and non-destructive way to detect the different functional groups that are present in the SAMs deposited onto metallic substrates and to acquire molecular information on these bi-dimensional systems. PM-IRRAS was performed on gold substrates modified with SAM 1, SAM 2, SAM 3 and SAM 4 and the spectra are shown in Figure 13 (a to d, respectively) in which characteristic bands could be identified. The bands at 2922, 2851 and $1465 \mathrm{~cm}^{-1}$ were assigned to antisymmetric $\left(\mathrm{V}_{\mathrm{a}} \mathrm{CH}_{2}\right)$ and symmetric $\left(v_{\mathrm{s}} \mathrm{CH}_{2}\right)$ stretching modes as well as the bending $\left(\mathrm{CCH}_{2}\right)$ mode of the methylene groups , respectively, which are present in all the four SAMs. ${ }^{[41,42]}$ Figure 13 (a) shows the IRRAS spectrum of SAM 1, revealing alkyne bands at $3325 \mathrm{~cm}^{-1}\left(\mathrm{vC} \equiv \mathrm{CH}\right.$, strong) and at $2122 \mathrm{~cm}^{-1}(v \mathrm{C} \equiv \mathrm{C}$, weak), which disappear after click reaction as shown in Figure 13(b) for SAM 2 ${ }^{[41]}$ For SAM 2, presence of ferrocene is confirmed by the bands at 3104 and $1106 \mathrm{~cm}^{-1}$ related to the stretching $\mathrm{vCH}$ mode and the breathing ring mode $(\mathrm{vCC})$, respectively ${ }^{[43-45]}$ In addition, the anchoring of the ferrocenyl derivative $\mathbf{8}$ is confirmed by the presence of the $\mathrm{C}=\mathrm{O}$ band at $1689 \mathrm{~cm}^{-1}$, corresponding to the thioacetate moiety. ${ }^{[41]}$ However, in SAM 2, the $v \mathrm{~N}_{3}$ band of azide at $2100 \mathrm{~cm}^{-1}$ appears after click reaction, suggesting that not all the ferrocenyl derivative $\mathbf{8}$ underwent click reaction which is normal for such kind of reaction on surface. ${ }^{[25,33]}$ IRRAS spectrum of SAM 3 in Figure 13 (c) exhibits the $v \mathrm{~N}_{3}$ band at 2100 $\mathrm{cm}^{-1}$ (confirming the presence of azide functional group) which diminishes after the click reaction in SAM 4, as shown in Figure 13 (d). Similar to SAM 2, presence of ferrocene is confirmed by the presence of the breathing $\mathrm{vCC}$ and $\mathrm{vCH}$ bands of the ferrocene ring at $1110 \mathrm{~cm}^{-1}$ and $3106 \mathrm{~cm}^{-1}$, 
respectively. Finally, anchoring of the ferrocenyl derivative $\mathbf{1 8}$ is confirmed by the presence of the $\mathrm{C}=\mathrm{O}$ band at $1690 \mathrm{~cm}^{-1}$ related to thiol acetate moiety.

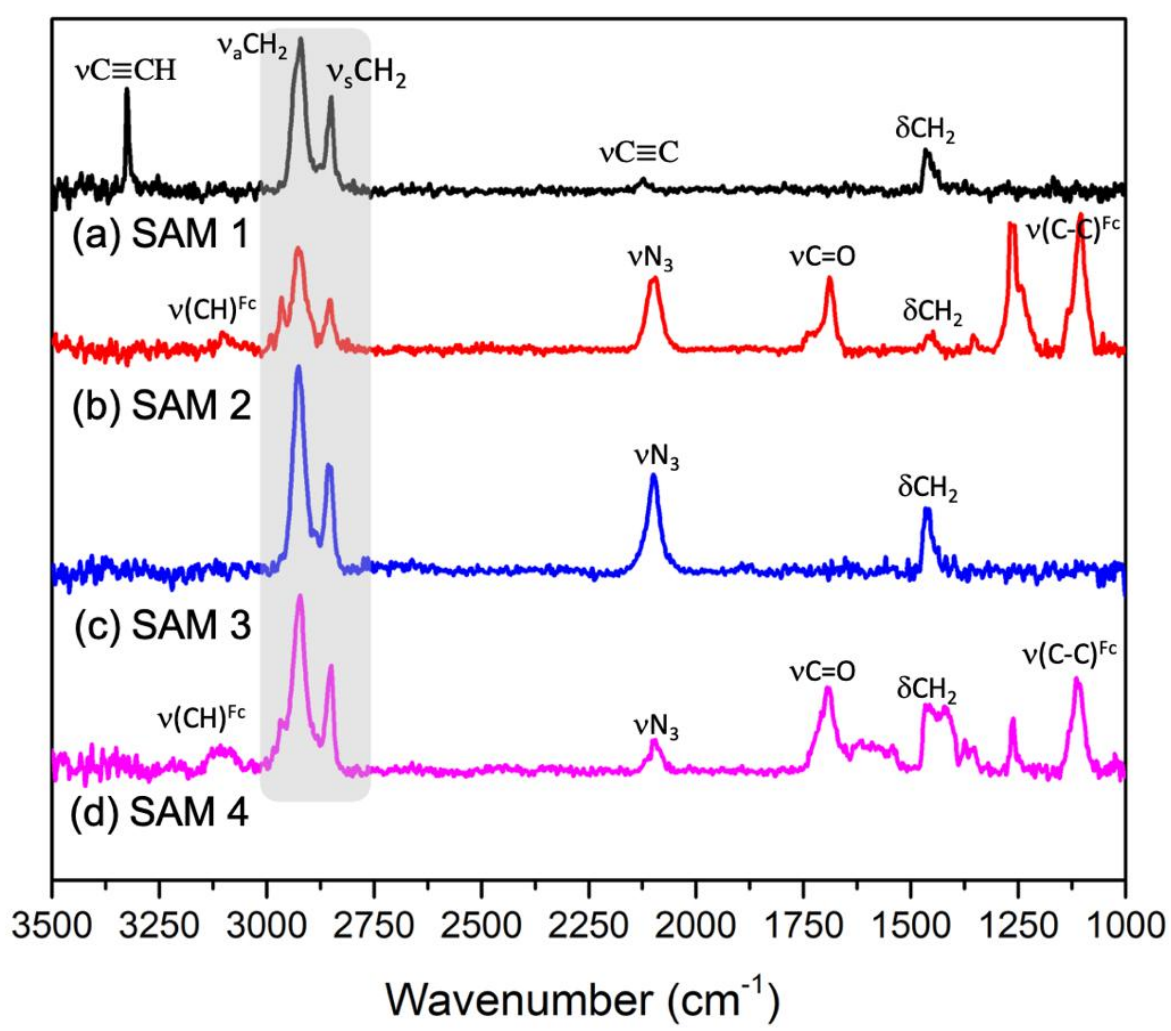

Figure 13. IRRAS spectra of (a) SAM 1, (b) SAM 2, (c) SAM 3 and (d) SAM 4 with bands of $\mathrm{CH}_{2}$ common to all four SAMs highlighted in grey box.

\subsection{XPS}

X-Ray Photoelectron Spectroscopy (XPS) provides important information on SAMs regarding the elements that are present on the surface of the substrates and their corresponding chemical states. XPS analyses of ferrocene-functionalized surfaces have previously been reported in the literature, enabling to an easier assignment of the different peaks. ${ }^{[46,47]}$ Thus, XPS analyses of SAM 2 and SAM 4 were performed to confirm the successful linkage of the ferrocenyl group to the thioalkyl chains of SAM 1 and SAM 3. Figures 14 and 15 show the XPS spectra of SAM 2 and SAM 4, respectively, in the $\mathrm{S} 2 \mathrm{p}, \mathrm{N} 1 \mathrm{~s}, \mathrm{Fe} 2 \mathrm{p}$ and $\mathrm{O} 1 \mathrm{~s}$ regions.

The S2p XPS spectra of SAM 2 and SAM 4 (see Figures 14a and 15a) showed a broad peak containing a convolution of two sets of doublets corresponding to the $S 2 p_{3 / 2}$ and the $S 2 p_{1 / 2}$ peaks. The $\mathrm{S} 2 \mathrm{p}_{3 / 2}$ peak of lower binding energy, centered at $162 \mathrm{eV}$, is associated to sulphur covalently bound to gold. The $S 2 p_{1 / 2}$ peak located at high energy, i.e. $163.5 \mathrm{eV}$, is associated to unbound $\mathrm{S}$ and thiol acetate group present at the top of the molecule. ${ }^{[48]}$ Hence, these different peaks confirm the presence of two types of sulphur atoms in the two SAMs. The success of the click reaction and the subsequent formation of a triazole ring were also evidenced with the N1s XPS spectra (see Figure 14b and 15b) by the presence of two peaks of binding energies $400.7 \mathrm{eV}$ and $402.1 \mathrm{eV}$. ${ }^{[25,40,46]}$ These two peaks at $400.7 \mathrm{eV}$ and $402.1 \mathrm{eV}$ are related to N-C and N-N bonds, respectively. ${ }^{[47,49,50]}$ Moreover, presence of iron and therefore of ferrocene on the metal surface is evidenced with Fe2p XPS spectra (see Figure $14 \mathrm{c}$ and $15 \mathrm{c}$ ), where a broad peak is detected at $707.5 \mathrm{eV}$ containing both the $\mathrm{Fe} 2 \mathrm{p}_{3 / 2}$ and the $\mathrm{Fe} 2 \mathrm{p}_{1 / 2}$ 
peaks. This result is in excellent agreement with the reported ferrocene molecule assembled on a surface. ${ }^{[51]}$ Finally, the O1s XPS spectra of (see Figures $14 \mathrm{~d}$ and $15 \mathrm{~d}$ ) exhibit a well-identified peak at $531 \mathrm{eV}$, and this binding energy is typical of $\mathrm{C}=\mathrm{O}$ functions. ${ }^{[52]}$ Only the presence of thioacetate can explain this peak, demonstrating a good ligation between the alkane chains and the ferrocene derivatives.
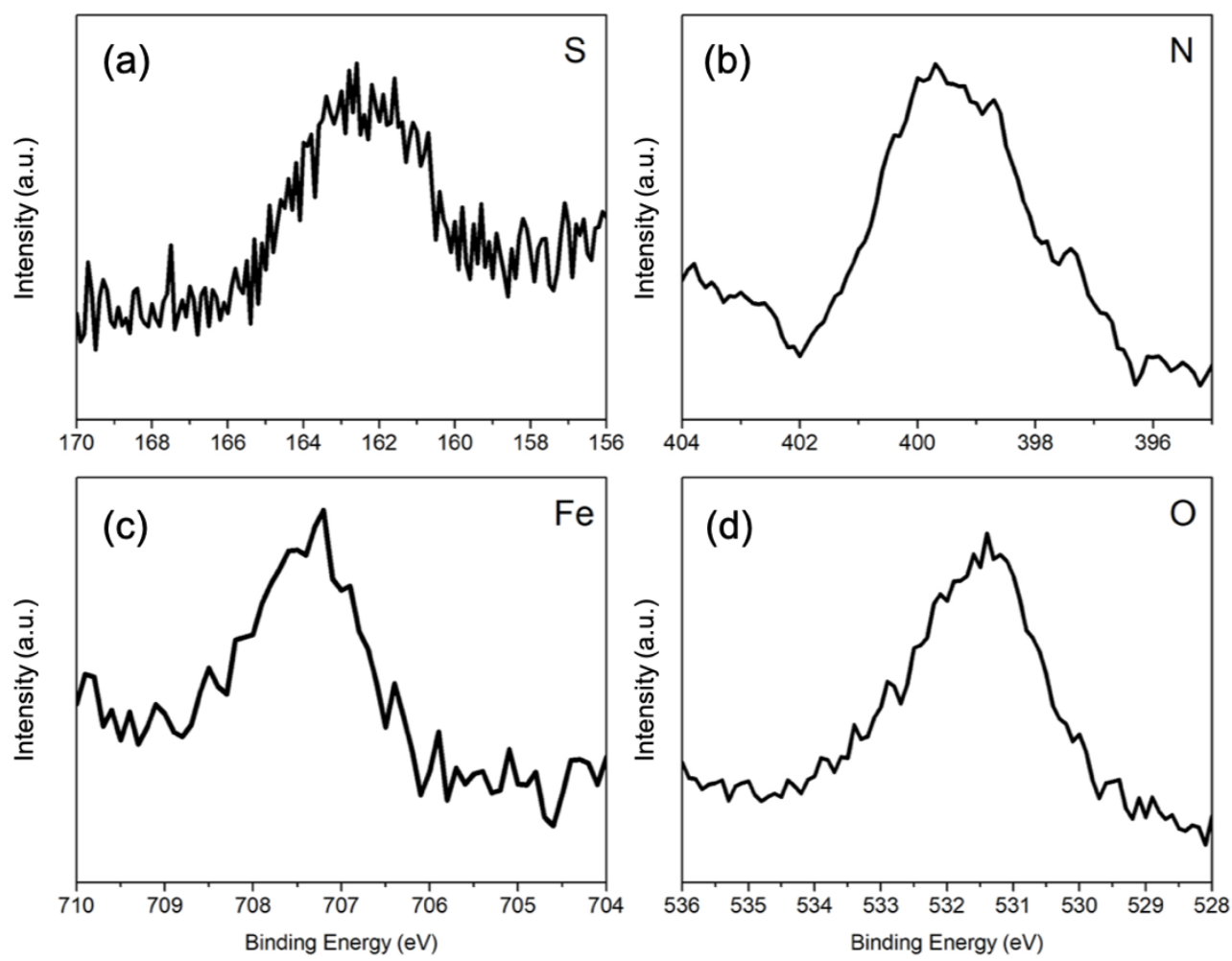

Figure 14. XPS spectra of SAM 2 with the elements (a) S; (b) N; (c) Fe and (d) $O$. 

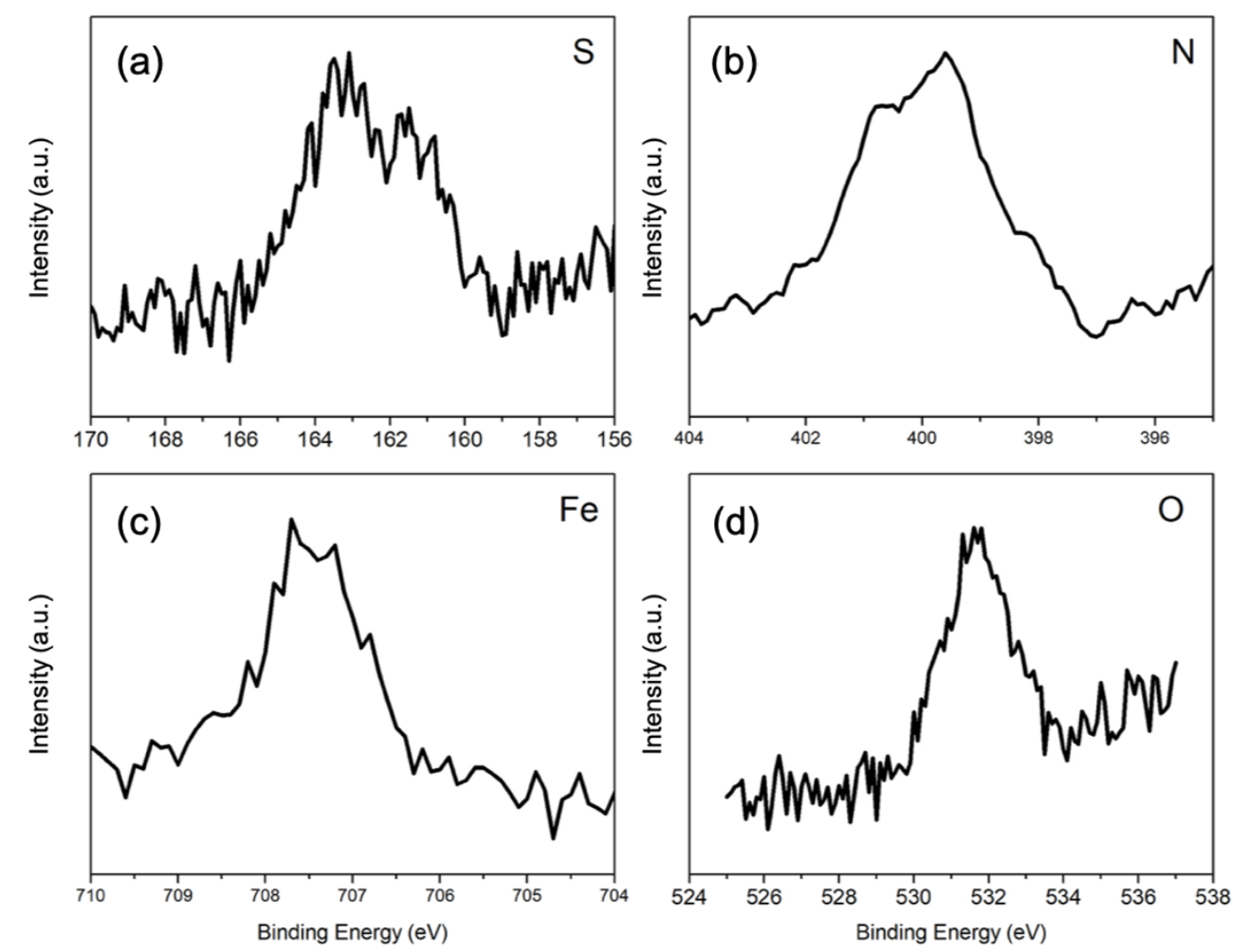

Figure 15. XPS spectra of SAM 4 with the elements (a) S; (b) N; (c) Fe and (d) O.

\subsection{Ellipsometry measurements}

Variable Angle Ellipsometry (VASE), a straightforward non-destructive tool, is used to determine the thicknesses of the different SAMs deposited on various substrates. ${ }^{[3,54]}$ The analysis is based on a double determination of refractive indexes and the SAM thickness which are precisely computed by iterative calculus until a $\mathrm{R}^{2} \approx 1$ value is reached. The acquired RMSE value from the fits for all incident angles are around 0.02 for all SAMs. In the case of SAM 2 and SAM 4, there is no exact value of refractive index of ferrocenyl-alkanethiol SAM, and, as a strong assumption, the value was taken at the beginning equals to the refractive index of the SAM of alkanethiol assuming no significant change in the refractive index after click reaction. Table 1 shows the thickness obtained for the different SAMs along with the associated refractive indexes. Increase in SAM thicknesses from SAM 1 to SAM 2 and SAM 3 to SAM 4 is in good agreement with the success of click reaction on surface. The obtained refractive index is around 1.49 , which is very close to the previously obtained value. $^{[33]}$

Table 1: Ellipsometry results.

\begin{tabular}{lcc}
\hline & Thickness $(\mathbf{n m})$ & Refractive index at $\boldsymbol{\lambda}=\mathbf{6 0 0} \mathbf{~ n m}$ \\
\hline SAM 1 & 0.85 & 1.53 \\
\hline SAM 2 & 2.04 & 1.45 \\
\hline
\end{tabular}




\begin{tabular}{lcc}
\hline SAM 3 & 1.15 & 1.49 \\
\hline SAM 4 & 2.13 & 1.48 \\
\hline
\end{tabular}

The $\mathrm{R}^{2}$ of all the measured SAM were above the value of 0.98 .

First, the SAM 1 seems to have a lower thickness than the SAM 3, which can be linked to the difference of length between 11-undecynethiol (alkane chain of 9 carbons) and 11-azido-undecanethiol (alkane chain of 11 carbons). Moreover, the slight thickness difference for the SAM 1 and SAM 3 can also be associated with the refractive index, describing self-assembly of different alkanethiol. The increase of around $1 \mathrm{~nm}$ of the thickness between the two steps of the reaction is associated with the covalent linkage of $\mathbf{8}$ and $\mathbf{1 8}$ ferrocenyl derivatives on top of the SAM 1 and SAM 3 to form SAM 2 and SAM 4, respectively.

\subsection{Contact angle measurement}

Contact angle measurements give information of the nature of the SAMs and are commonly used as a characterization tool to determine the hydrophilic or the hydrophobic modification of the surface. In our case, from the hydrophilic bare gold electrode to hydrophobic first layers and terminated by the slightly hydrophilic complete monolayers, contact angle measurements can be used to monitor the different reaction steps. The various organic functions present in our systems have already been studied. ${ }^{[55,56]}$ Table 2 shows the values of contact angle measurements for the four SAMs and the gold substrate.

Table 2: Contact angle value (with water).

\begin{tabular}{lc}
\hline & Contact Angle with water $\left(^{\circ}\right)$ \\
\hline Gold & $77 \pm 1.8$ \\
\hline SAM 1 & $87.3 \pm 1$ \\
\hline SAM2 & $74.4 \pm 3.1$ \\
\hline SAM 3 & $70.9 \pm 1.5$ \\
\hline SAM 4 & $73.9 \pm 2.3$ \\
\hline
\end{tabular}

It is concluded from the high contact angle that the SAM $\mathbf{1}$ is hydrophobic as shown in table 2. There are no documented reports about the contact angle measurements of alkyne thiol selfassembled monolayers on gold, but by comparison with the literature ${ }^{[57,58]}$ the values of angles determined for the SAMs composed of long alkyl chains terminated by alkyne functions are around $80^{\circ}$. In our case, we obtained value of $87^{\circ}$ for SAM 1 and $71^{\circ}$ for SAM 3 as alkyne is more hydrophobic than azide and these values are also lower than the values of pure alkanethiol chains on gold (i.e., $110^{\circ}$ ). ${ }^{[59]}$ This value is relevant with a mixed SAM of alkyne and alkane chain. For the SAM 1, the angle value is higher and representative of a hydrophobic SAM. But the research of Spruell reported a lower contact angle of $76.5^{\circ}$ for mixed SAMs composed of undecynethiol/octanethiol $(50 \% / 50 \%) .{ }^{[56]}$ The relative difference between their values and our values is around $13 \%$. Such a difference can be explained by the difference of substrates. In the case of 
Spruell's work, they worked with gold evaporated on titanium, giving gold substrate more rugose than the template stripped substrates used in this work. Moreover, higher value of contact angle reflects better packing or lower interactions of water molecules with the deposited molecules ${ }^{[60]}$ The contact angle value determined for SAM 2 decreases and SAM 4 increases as compared to SAM 1 and SAM 3, respectively. In the literature, thioacetate (the function in direct contact with the drop of water) is considered as a hydrophilic function, associated to a low contact angle $\left(70^{\circ}\right) .^{[60]}$ If the angle value is slightly higher, this can be explained by the presence of the ferrocene group, a hydrophobic moiety, which can be also on contact with the drop giving statistically a surface with hydrophobic point and hydrophilic point. This point is supported by the fact that the standard deviation for SAM 2 and SAM 4 is higher than for SAM 1 and SAM 3.

\section{Conclusion}

Ferrocene-based SAMs comprising aliphatic and aromatic chains are extensively studied since the early 1990s. Besides, the fabrication of SAMs based on molecules bearing thiol groups at both ends is a real challenge. This study constitutes an original extension of the work done by Hamoudi and coworkers ${ }^{[8]}$ who attempted to functionalize metal surfaces with dithiol molecules. Unfortunately, the presence of the two reactive groups on the same molecules only produced SAMs of poor quality, due to the connection of the two thiol groups onto the surface or the connection between molecules by disulfide bond formation. In this study, this issue was addressed by developing a two-step procedure for the functionalization of gold surfaces. To achieve this goal, we notably selected a high-yielding reaction, namely the Copper catalysed Alkyne Azide Cycloaddition (CuAAC) reaction also named "click chemistry" to form the covalent bond between the SAMs deposited on gold substrate and our functionalizing agent, namely, the ferrocene derivatives. We have notably demonstrated the synthesis of two ferrocenes-derived alkyl chains $\mathbf{F c 1}$ and Fc2 by combining 3 and $\mathbf{1 2}$ with $\mathbf{8}$ and 18, respectively, thanks to a CuAAC click reaction. To improve the quality and the orientation of SAMs, the SAMs based on Fc1 and Fc2 have been fabricated by a two-step click chemistry reaction directly done on gold substrates. Cyclic voltammetry done on SAM 1 and SAM 3 revealed the presence of an insulating mixed-thiol monolayer and the subsequent measurements done on SAM 2 and SAM 4 confirmed the success of the click reaction, by the clear appearance of a redox peak associated to the presence of ferrocene. The molecular surface density has also been quantified by integrating the redox peaks which revealed that the SAM 4 had a higher packing density of $64 \%$ than the SAM 2 which only exhibited $43 \%$ of the total theoretical area coverage by the ferrocene-alkanethiols.

Surface analyses performed in this study show that it is possible to realize SAMs containing two anchoring groups, with a well-controlled architecture for the whole system. PM-IRRAS analyses revealed the presence of click active functional groups in SAM 1 and SAM 3 which diminishes after click reaction with the $\mathbf{8}$ and $\mathbf{1 8}$ moieties containing ferrocene derivative. Furthermore, XPS revealed the presence of all the required elements on gold with the expected oxidation and specially XPS of nitrogen revealing the presence of triazole confirming click reaction. Ellipsometry characterization determined the thickness of SAM 1 and SAM 3 with excellent agreement with the reported values in the literature and increase of thickness from $0.85 \mathrm{~nm}$ to 2.04 for $\mathbf{F c 1}$ and from $1.15 \mathrm{~nm}$ to $2.13 \mathrm{~nm}$ for Fc2. Contact angle measurements showed the modification of hydrophilicity of the surface after SAM deposition and during the different reaction step, evidencing the chemical modification occurring at the surface of the substrate. Future works will consist in controlling the position of ferrocene moiety on the carbon chain and in the modification of the number of carbons on the molecule for applications such as molecular electronics where the spatial position of ferrocene and overall, the length of the molecule plays a crucial role in electron tunnelling between the two electrodes enhancing properties such as current rectification. Moreover, this work can be extended to other applications requiring different active groups replacing ferrocene with targeted functional moieties. 
Thanks to click chemistry, it is possible to anchor new compounds with required functional group and multiple anchoring groups. With click chemistry, such new SAM configuration can be very interesting in order to realize new electronic devices.

\section{Experimental}

All reagents and solvents were purchased from Aldrich, Alfa Aesar, Flurochem or TCI Europe and used as received without further purification. Mass spectroscopy was performed by the Spectropole of Aix-Marseille University. ESI mass spectral analyses were recorded with a 3200 QTRAP (Applied Biosystems SCIEX) mass spectrometer. The HRMS mass spectral analysis was performed with a QStar Elite (Applied Biosystems SCIEX) mass spectrometer. Elemental analyses were recorded with a Thermo Finnigan EA 1112 elemental analysis apparatus driven by the Eager 300 software. ${ }^{1} \mathrm{H}$ and ${ }^{13} \mathrm{C}$ NMR spectra were determined at room temperature in $5 \mathrm{~mm}$ o.d. tubes on a Bruker Avance 400 spectrometer of the Spectropole: ${ }^{1} \mathrm{H}(400 \mathrm{MHz})$ and ${ }^{13} \mathrm{C}(100 \mathrm{MHz})$. The ${ }^{1} \mathrm{H}$ chemical shifts were referenced to the solvent peak $\mathrm{CDCl}_{3}(7.26 \mathrm{ppm})$ and the ${ }^{13} \mathrm{C}$ chemical shifts were referenced to the solvent peak $\mathrm{CDCl}_{3}$ (77 ppm). Synthesis of 11- (undec- 1-ynyl)methylsulfonate $2{ }^{[26]}$, 11(undecynyl)thioacetate $\mathbf{3}{ }^{[26]} 11$-(undecynyl)thiol $4,{ }^{[26]}$ diformylferrocene $5,{ }^{[27]}$ ferrocenedimethanol $\mathbf{6}$ , ${ }^{[28]} 1$-(azidomethyl)-1'-(hydroxymethyl)ferrocene $7,{ }^{[28]} 11$-azidoundecanol $\mathbf{1 0},{ }^{[31]}$ 11-azido-1methylsulfonatedecane $11,{ }^{[31]} 11$-azidoundecan-1-thioacetate $18,{ }^{[31]} 11$-azidoundecane-1-thiol $19,{ }^{[31]}$ 1-acetyl-1'-formylferrocene $14{ }^{\text {[32Erreur ! Signet non défini.] }}$ (1-chloro-2-formyvin-1-yl) -1'-formylferrocene $15,{ }^{[32]} 1$-formyl-1' -ethynylferrocene $16^{[32]}$ were synthesized following the procedures described in the literature.

\section{Fabrication of gold substrates}

Ultra-flat template-stripped gold substrates $\left(\mathrm{Au}^{\mathrm{TS}}\right)$ were fabricated following the method reported by Thou et al. ${ }^{[61]}$ Gold layer of thickness around $200 \mathrm{~nm}$ was deposited by e-beam evaporation on commercial Si (100) wafer followed by annealing at $200^{\circ} \mathrm{C}$ for 20 minutes. Glass pieces of dimension $1.5 \times 1.5 \mathrm{~cm}$ are cleaned in distilled water, ethanol and finally isopropanol in an ultrasonic bath and dried under a nitrogen flow and put in an oxygen plasma for 2 minutes. Then, using a Norland61 ultraviolet (UV) curing optical adhesive, each piece of clean glass is glued to the wafer. The wafer is then placed under UV light for 1 hour to cure the adhesive. Each individual glass sample is then stripped from the wafer less than 30s before being immersed in the molecular solution for SAM deposition.

\section{Realization of SAM}

The freshly template stripped $\mathrm{Au}^{\mathrm{TS}}$ substrates were soaked in $10 \mathrm{mM}$ degassed solution of the long alkanethiol chain (typically $1,15 \mathrm{mg}$ of 11 -azidoundecanethiol and $0.73 \mathrm{mg}$ of octanethiol for SAM 3 SAM 4 and $0.92 \mathrm{mg}$ of 11-(undecynyl) thiol and $0.73 \mathrm{mg}$ of octanethiol for SAM 1, SAM 2) for 24 hours in inert environment. After cleaning the substrates for the first step (SAM 1, SAM3) with ethanol. The substrates were immerged in a solution of $1 \mathrm{mM}$ total of the ferrocenyl derivates (typically $3.3 \mathrm{mg}$ for SAM 2 and $3 \mathrm{mg}$ for SAM 4) in $5 \mathrm{~mL}$ of degassed ethanol, then $2.5 \mathrm{~mL}$ of a 0.01 $\mathrm{mM}$ of copper sulfate aqueous degassed solution was added and after this $2.5 \mathrm{~mL}$ of $0.01 \mathrm{mM}$ of sodium ascorbate aqueous degassed solution was added. The reaction was stirred for $24 \mathrm{~h}$ at room temperature under inert environment. After removing them from solution, the substrates were rinsed with ethanol, dichloromethane, water and then big amount of ethanol. Then, the substrates were dried with argon.

\section{Electrochemical}

$\mathrm{CV}$ measurements were carried out in a custom-built electrochemical cell with three outlets at the top for degassing, counter electrode and reference electrode and one outlet at the bottom to assemble working electrode. A platinum wire was used as the counter electrode, an $\mathrm{Ag} / \mathrm{AgCl}$ reference electrode and $\mathrm{Au}^{\mathrm{TS}}$ served as the working electrode. Cyclic voltammograms were recorded in an aqueous 
solution of $1 \mathrm{M} \mathrm{HClO}_{4}$ using AUTOLAB PGSTAT302N potentiostat. NOVA 2 software was used to record $\mathrm{CV}$ between -0.1 to $0.9 \mathrm{~V}$ at a scan rate varying from $100 \mathrm{mV} / \mathrm{s}$ to1 V/s.

\section{PM-IRRAS}

PM-IRRAS spectra were recorded on a ThermoNicolet Nexus 670 FTIR spectrometer at a resolution of $4 \mathrm{~cm}^{-1}$, by coadding several blocks' of 1500 scans ( 30 minutes acquisition time). All spectra were collected in a dry-air atmosphere, and generally eight blocks (4 hours acquisition time) were necessary to obtain PM-IRRAS spectra of SAMs with good signal-to-noise ratios. Experiments were performed at an incidence angle of $75^{\circ}$ using an external homemade goniometer reflection attachment. The infrared parallel beam (modulated in intensity at frequency $f_{\mathrm{i}}$ lower than $5 \mathrm{KHz}$ ) was directed out of the spectrometer with an optional flipper mirror and made slightly convergent with a first $\mathrm{BaF}_{2}$ lens (191 mm focal length). The IR beam passed through a $\mathrm{BaF}_{2}$ wire grid polarizer (Specac) to select the p-polarized radiation and a $\mathrm{ZnSe}$ photoelastic modulator (PEM, Hinds Instruments, type III). The PEM modulated the polarization of the beam at a high fixed frequency, $2 f_{\mathrm{m}}=100 \mathrm{KHz}$, between the parallel and perpendicular linear states. After reflection on the sample, the double modulated (in intensity and in polarization) infrared beam was focused with a second $\mathrm{ZnSe}$ lens ( $38.1 \mathrm{~mm}$ focal length) onto a photovoltaic MCT detector (Kolmar Technologies, Model KV104) cooled at $77 \mathrm{~K}$. In all experiments, the PEM was adjusted for a maximum efficiency at $2500 \mathrm{~cm}^{-1}$ to cover the mid-IR range in only one spectrum. For calibration measurements, a second linear polarizer (oriented parallel or perpendicular to the first preceding the PEM) was inserted between the sample and the second $\mathrm{ZnSe}$ lens. This procedure was used to calibrate and convert the PM-IRRAS signal in terms of the IRRAS signal (i.e., $1-R p(d) / R p(0)$ where $R p(d)$ and $R p(0)$ stand for the p-polarized reflectance of the film/substrate and bare substrate systems, respectively). ${ }^{[62]}$

\section{XPS}

XPS experiments were performed in a UHV system at $10^{-9}$ mbar with a monochromatized $\mathrm{Al} \mathrm{K} \alpha \mathrm{X}$ ray radiation $(1486.7 \mathrm{eV})$ of an Omicron XM1000 source. Spectra were recorded at $20^{\circ}$ emission angle with an Omicron EA125 analyzer and a $30 \mathrm{eV}$ pass energy. Gaussian-Lorentzian (30\%) components were used for the deconvolution of the XPS spectra after subtraction of a Shirley background.

\section{Ellipsometry}

Variable Angle Ellipsometry (VASE) was used to determine the thicknesses of the different SAMs deposited on Au substrate. Semilab rotating compensator ellipsometer (RCE) with a microspot was used to focus the beam on the samples. Data measurements were done for wavelengths ranging between 400 and $650 \mathrm{~nm}$ at three incidence angles $\left(65^{\circ}, 70^{\circ}\right.$, and $\left.75^{\circ}\right)$. Ellipsometric data was fit with the help of SEA software (Semilab). The combined Drude-Lorentz oscillator dispersion law has been used to calculate the dielectric constant determination of gold substrate. ${ }^{[63]}$ A Sellmeier model was used to describe the presence of SAM.

\section{Contact Angle}

The contact angle measurements were performed with an OCA 15EC from Dataphysics in ambient condition at room temperature $\left(21.2^{\circ} \mathrm{C}\right)$. A $1 \mathrm{~mL}$ syringe $M O D E L$ filled with DI water was used to form a drop of $2.5 \mu \mathrm{L}$. Five drops were deposited on each sample and, for each drop, the contact angles on both side of the drop were measured and then averaged.

\section{Synthesis of 1-azidomethyl-1'-thioacetylmethylferrocene 8.}

To a solution of 1-azidomethyl-1'-hydromethylferrocene $7(0.45 \mathrm{~g}, 1.66 \mathrm{mmol}, 1$ equiv. $)$ in acetone $(25 \mathrm{~mL})$ was added thioacetic acid $(142 \mu \mathrm{L}, \mathrm{mmol}, 1.99 \mathrm{mmol}, 1.2$ equiv.) and $10 \mu \mathrm{L}$ of trifluoracetic acid as the catalyst. The mixture was stirring overnight at room temperature. The mixture was 
partitioned between water $(100 \mathrm{~mL})$ and diethyl ether $(100 \mathrm{~mL})$. The organic phase was separated and washed with brine, dried with $\mathrm{MgSO}_{4}$. The solvent was evaporated in vacuo to give $0.46 \mathrm{~g}$ ( $84 \%$ yield) of an orange oil.

${ }^{1} \mathrm{H}$ NMR $\left(300 \mathrm{MHz}, \mathrm{CDCl}_{3}\right) \delta 4.29-4.07$ (m, 10H), 3.89 (s, 2H), $2.33(\mathrm{~s}, 3 \mathrm{H})$.

${ }^{13} \mathrm{C}$ NMR $\left(75 \mathrm{MHz}, \mathrm{CDCl}_{3}\right) \delta 195.4,85.1,82.8,69.8,69.5,69.0,50.9,30.5,29.1$.

HRMS (ESI MS) m/z: theor: 329.0280 found: $329.0280\left([\mathrm{M}]^{+.}\right.$detected)

\section{Synthesis of Fc1.}

To a well-stirred solution of 1-azidomethyl-1'-thioacetylmethylferrocene $8(0.498 \mathrm{~g}, 1.51 \mathrm{mmol}, 1$ equiv.) and 11-(undecynyl)thioacetate $3\left(0.342 \mathrm{~g}, 1.51 \mathrm{mmol}, 1\right.$ equiv.) in $\mathrm{EtOH} / \mathrm{H}_{2} \mathrm{O}(1: 1)(10 \mathrm{~mL})$ $\mathrm{CuSO}_{4} .5 \mathrm{H}_{2} \mathrm{O}(0.094 \mathrm{~g}, 378 \mu \mathrm{mol}, 0.25$ equiv. $)$ was added followed by sodium ascorbate $(0.075 \mathrm{~g}, 378$ $\mu$ mol, 0.25 equiv.). The reaction mixture was stirred for one day at room temperature. Ethyl acetate $(60 \mathrm{~mL})$ was added into the reaction mixture, the organic phase was washed with water, and then brine. After drying with $\mathrm{MgSO}_{4}$ and evaporation of ethyl acetate, the crude product was purified by column chromatography $\left(\mathrm{SiO}_{2}\right)$ using ether as the eluent. The product was isolated as a yellow solid (0.8 g, $95 \%$ yield).

${ }^{1} \mathrm{H}$ NMR $\left(300 \mathrm{MHz}, \mathrm{CDCl}_{3}\right) \delta 7.16(\mathrm{~s}, 1 \mathrm{H}), 5.25(\mathrm{~s}, 2 \mathrm{H}), 4.28-4.08(\mathrm{~m}, 8 \mathrm{H}), 3.87(\mathrm{~s}, 2 \mathrm{H}), 2.85(\mathrm{t}, J=$ $7.3 \mathrm{~Hz}, 2 \mathrm{H}), 2.71-2.59(\mathrm{~m}, 2 \mathrm{H}), 2.32(\mathrm{~d}, J=5.6 \mathrm{~Hz}, 6 \mathrm{H}), 1.66-1.52(\mathrm{~m}, 4 \mathrm{H}), 1.27(\mathrm{~s}, 10 \mathrm{H})$.

${ }^{13} \mathrm{C}$ NMR $\left(101 \mathrm{MHz}, \mathrm{CDCl}_{3}\right) \delta 196.0,195.2,171.1,119.9,85.2,81.8,69.9,69.6,69.5,69.1,68.1$, $60.4,49.6,30.6,30.3,29.5,29.4,29.3,29.3,29.2,29.2,29.1,29.0,29.0,28.8,28.76,28.69,28.4$, $25.7,21.0,18.4,14.2$.

HRMS (ESI MS) m/z: theor: 578.1569 found: $578.1576\left([\mathrm{M}+\mathrm{Na}]^{+} \text {detected}\right)^{-15}$

\section{Synthesis of 1-ethynyl-1'-hydroxymethylferrocene 17.}

To a solution of 1-formy-1'-ethynylferrocene $\mathbf{1 6}$ (1.24 g, $5.21 \mathrm{mmol}, 1$ equiv.) in $20 \mathrm{~mL} \mathrm{MeOH}$ was added $\mathrm{NaBH}_{4}(0.254 \mathrm{~g}, 6.71 \mathrm{mmol}, 1.3$ equiv. $)$ at $0{ }^{\circ} \mathrm{C}$ and the mixture was stirred at room temperature for 1-2 h. The reaction mixture was quenched with $2 \mathrm{~N}$ aqueous $\mathrm{HCl}$. Then, $\mathrm{H}_{2} \mathrm{O}$ was added and the aqueous phase was extracted with $\mathrm{CH}_{2} \mathrm{Cl}_{2}$ two times. The combined organic extracts were dried over $\mathrm{MgSO}_{4}$, filtered, and concentrated under reduced pressure. The crude product was chromatographied on $\mathrm{SiO}_{2}$ using $\mathrm{CH}_{2} \mathrm{Cl}_{2}$ as the eluent. It gave the pure product as an orange oil $(0.91$ g, $73 \%$ yield).

${ }^{1} \mathrm{H}$ NMR (300 MHz, CDCl $) \delta 4.49-4.39(\mathrm{~m}, 4 \mathrm{H}), 4.29(\mathrm{~s}, 2 \mathrm{H}), 4.21(\mathrm{~d}, J=7.3 \mathrm{~Hz}, 4 \mathrm{H}), 2.81(\mathrm{~s}, 1 \mathrm{H})$.

${ }^{13} \mathrm{C} \mathrm{NMR}\left(75 \mathrm{MHz}, \mathrm{CDCl}_{3}\right) \delta 109.1,90.2,82.4,74.7,72.2,69.8,69.2,69.0,60.3$.

HRMS (ESI MS) m/z: theor: 241.0310 found: $241.0308\left([\mathrm{M}+\mathrm{H}]^{+\cdot}\right.$ detected)

\section{Synthesis of 1-ethynyl-1'-thioacetylmethylferrocene 18.}

To a solution of 1-ethynyl-1'-hydroxymethylferrocene $\mathbf{1 7}(1.23 \mathrm{~g}, 5.12 \mathrm{mmol}, 1$ equiv.) in acetone (30 $\mathrm{mL})$ was added thioacetic acid $(551 \mu \mathrm{L}, 7.68 \mathrm{mmol}, 1.5$ equiv.) and $10 \mu \mathrm{L}$ of trifluoroacetic acid as the catalyst. The mixture was stirring overnight at room temperature. The mixture was partitioned between water $(100 \mathrm{~mL})$ and diethyl ether $(100 \mathrm{~mL})$. The organic phase was separated, and the organic phase was washed with brine, dried over $\mathrm{MgSO}_{4}$, and the solvent evaporated in vacuo to give the crude product. Purification by column chromatography $\left(\mathrm{SiO}_{2}\right.$, Dichloromethane) gave $1.19 \mathrm{~g}$ (78\% yield) of an orange oil.

${ }^{1} \mathrm{H}$ NMR $\left(400 \mathrm{MHz}, \mathrm{CDCl}_{3}\right) \delta 4.44(\mathrm{t}, J=1.8 \mathrm{~Hz}, 2 \mathrm{H}), 4.20(\mathrm{~d}, J=1.5 \mathrm{~Hz}, 4 \mathrm{H}), 4.17-4.15(\mathrm{~m}, 2 \mathrm{H})$, $3.93(\mathrm{~s}, 2 \mathrm{H}), 2.77$ (s, 1H), 2.32 (s, 3H). 
${ }^{13} \mathrm{C}$ NMR $\left(101 \mathrm{MHz}, \mathrm{CDCl}_{3}\right) \delta 195.4,85.1,82.1,74.4,72.6,70.5,70.3,69.6,30.5,28.5$.

FTIR $\left(\mathrm{cm}^{-1}\right): 2110,1689(\mathrm{C}=\mathrm{O}$ of thioacetate group).

HRMS (ESI MS) m/z: theor: 299.0188 found: $299.0193\left([\mathrm{M}+\mathrm{H}]^{+} \cdot\right.$ detected $)$

\section{Synthesis of Fc2.}

To a well-stirred solution of azide $11(0.7 \mathrm{~g}, 2.35 \mathrm{mmol}, 1$ equiv. $)$ and alkyne $\mathbf{1 8}(0.571 \mathrm{~g}, 2.35 \mathrm{mmol}$, 1 equiv.) in $\mathrm{EtOH} / \mathrm{H}_{2} \mathrm{O}(1: 1)(10 \mathrm{~mL}), \mathrm{CuSO}_{4} .5 \mathrm{H}_{2} \mathrm{O}(0.093 \mathrm{~g}, 0.60 \mathrm{mmol}, 0.26$ equiv. $)$ was added followed by sodium ascorbate $(0.116 \mathrm{~g}, 0.62 \mathrm{mmol}, 0.27$ equiv.). The reaction mixture was stirred for one day at room temperature. Ethyl acetate $(60 \mathrm{~mL})$ was added into the reaction mixture. The organic phase was washed with brine $(15 \mathrm{~mL})$ and filtered through anhydrous magnesium sulfate. After evaporation of ethyl acetate, the crude product obtained was chromatographed with $\mathrm{Et}_{2} \mathrm{O}$ to give $1 \mathrm{~g}$ (78\% yield) of yellow solid.

${ }^{1} \mathrm{H}$ NMR $\left(400 \mathrm{MHz}, \mathrm{CDCl}_{3}\right) \delta 7.49(\mathrm{~s}, 1 \mathrm{H}), 4.71(\mathrm{~d}, J=1.7 \mathrm{~Hz}, 2 \mathrm{H}), 4.35(\mathrm{t}, J=7.2 \mathrm{~Hz}, 2 \mathrm{H}), 4.29(\mathrm{~d}$, $J=1.6 \mathrm{~Hz}, 2 \mathrm{H}), 4.06(\mathrm{~d}, J=1.6 \mathrm{~Hz}, 2 \mathrm{H}), 4.03(\mathrm{~d}, J=1.7 \mathrm{~Hz}, 2 \mathrm{H}), 3.65(\mathrm{~s}, 2 \mathrm{H}), 2.85(\mathrm{t}, J=7.3 \mathrm{~Hz}$, $2 \mathrm{H}), 2.30(\mathrm{~d}, J=14.9 \mathrm{~Hz}, 6 \mathrm{H}), 1.97-1.88(\mathrm{~m}, 2 \mathrm{H}), 1.55(\mathrm{dt}, J=14.9,7.3 \mathrm{~Hz}, 2 \mathrm{H}), 1.33(\mathrm{~s}, J=28.6$ $\mathrm{Hz}, 10 \mathrm{H})$.

${ }^{13} \mathrm{C}$ NMR $\left(101 \mathrm{MHz}, \mathrm{CDCl}_{3}\right) \delta 196.1,195.2,147.0,119.3,118.9,85.6,85.0,75.0,70.5,70.3,70.2$, $70.1,70.0,69.9,69.8,69.5,68.1,67.4,67.2,50.5,49.1,30.8,30.4,29.7,29.6,29.5,29.4,29.3,29.2$, 29.1, 29.0, 28.9, 28.8, 28.6, 26.7.

HRMS (ESI MS) m/z: theor: 592.1726 found: $592.1724\left([\mathrm{M}+\mathrm{Na}]^{+.}\right.$detected)

\section{Acknowledgments}

Damien Brunel and Vikas Jangid contributed equally to this work.

This project has received funding from the Direction Générale de l'Armement (DGA) and is acknowledged for its financial support through the PhD grant of Damien Brunel. This project has also received funding from the European Union's Horizon 2020 research and innovation programme under the Marie Skłodowska-Curie grant agreement No713750 for the PhD grant of Vikas Jangid. Also, it has been carried out with the financial support of the Regional Council of Provence- Alpes-Côte d'Azur and with the financial support of the A*MIDEX ( $\mathrm{n}^{\circ}$ ANR-11-IDEX-0001-02), funded by the Investissements d'Avenir project funded by the French Government, managed by the French National Research Agency (ANR).).

\section{References}

${ }^{[1]}$ C. Vericat, M.E. Vela, G. Benitez, P. Carro, R.C. Salvarezza, Self-assembled monolayers of thiols and dithiols on gold: new challenges for a well-known system, Chem. Soc. Rev. 39 (2010) 1805-1834. https://doi.org/10.1039/B907301A.

${ }^{[2]}$ J.C. Love, L.A. Estroff, J.K. Kriebel, R.G. Nuzzo, G.M. Whitesides, Self-Assembled Monolayers of Thiolates on Metals as a Form of Nanotechnology, Chem. Rev. 105 (2005) 1103-1170. https://doi.org/10.1021/cr0300789.

${ }^{[3]}$ A. Ulman, Formation and Structure of Self-Assembled Monolayers, Chem. Rev. 96 (1996)1533-1554. https://doi.org/10.1021/cr9502357

${ }^{[4]}$ S.K. Arya, P.R. Solanki, M. Datta, B.D. Malhotra, Recent advances in self-assembled monolayers based biomolecular electronic devices, Biosensors and Bioelectronics. 24 (2009) 2810-2817. https://doi.org/10.1016/j.bios.2009.02.008.

${ }^{[5]}$ M. Singh, N. Kaur, E. Comini, The role of self-assembled monolayers in electronic devices, J. Mater. Chem. C. 8 (2020) 3938-3955. https://doi.org/10.1039/D0TC00388C. 
${ }^{[6]}$ A.R. Bishop, R.G. Nuzzo, Self-assembled monolayers: Recent developments and applications, Curr. Opin. Colloid Interface Sci. 1 (1996) 127-136. https://doi.org/10.1016/S1359-0294(96)80053-7.

[7] F. Dumur, E. Dumas, C.R. Mayer, Functionalization of gold nanoparticles by inorganic entities, Nanomaterials 10 (2020) 548. https://doi.org/10.3390/nano10030548.

${ }^{[8]}$ H. Hamoudi, V.A. Esaulov, Selfassembly of $\alpha, \omega$-dithiols on surfaces and metal dithiol heterostructures, Annalen Der Physik. 528 (2016) 242-263. https://doi.org/10.1002/andp.201500280.

${ }^{[9]}$ N. Xin, J. Guan, C. Zhou, X. Chen, C. Gu, Y. Li, M.A. Ratner, A. Nitzan, J.F. Stoddart, X. Guo, Concepts in the design and engineering of single-molecule electronic devices, Nature Reviews Physics. 1 (2019) 211-230. https://doi.org/10.1038/s42254-019-0022-x.

${ }^{[10]}$ V. Castro, H. Rodríguez, F. Albericio, CuAAC: An Efficient Click Chemistry Reaction on Solid Phase, ACS Comb. Sci. 18 (2016) 1-14. https://doi.org/10.1021/acscombsci.5b00087.

${ }^{[11]}$ J. Escorihuela, A.T.M. Marcelis, H. Zuilhof, Metal-Free Click Chemistry Reactions on Surfaces, Advanced Materials Interfaces. 2 (2015) 1500135. https://doi.org/10.1002/admi.201500135.

${ }^{[12]}$ P. Yáñez-Sedeño, A. González-Cortés, S. Campuzano, J.M. Pingarrón, Copper(I)-Catalyzed Click Chemistry as a Tool for the Functionalization of Nanomaterials and the Preparation of Electrochemical (Bio)Sensors, Sensors. 19 (2019) 2379. https://doi.org/10.3390/s19102379.

${ }^{[13]}$ S.M.M. Dadfar, S. Sekula-Neuner, V. Trouillet, M. Hirtz, A Comparative Study of Thiol-Terminated Surface Modification by Click Reactions: Thiol-yne Coupling versus Thiol-ene Michael Addition, Advanced Materials Interfaces. 5 (2018) 1801343. https://doi.org/10.1002/admi.201801343.

${ }^{[14]}$ S.M.M. Dadfar, S. Sekula-Neuner, V. Trouillet, M. Hirtz, Protein Microarray Immobilization via Epoxide Ring-Opening by Thiol, Amine, and Azide, Advanced Materials Interfaces. 8 (2021) 2002117. https://doi.org/10.1002/admi.202002117.

${ }^{[15]}$ S.M.M. Dadfar, S. Sekula-Neuner, V. Trouillet, H.-Y. Liu, R. Kumar, A.K. Powell, M. Hirtz, Evaluation of click chemistry microarrays for immunosensing of alpha-fetoprotein (AFP), Beilstein Journal of Nanotechnology. 10 (2019) 2505-2515. https://doi.org/10.3762/bjnano.10.241.

${ }^{[16]}$ S.M.M. Dadfar, S. Sekula-Neuner, U. Bog, V. Trouillet, M. Hirtz, Site-Specific Surface Functionalization via Microchannel Cantilever Spotting $(\mu \mathrm{CS})$ : Comparison between Azide-Alkyne and Thiol-Alkyne Click Chemistry Reactions, Small. 14 (2018) 1800131. https://doi.org/10.1002/smll.201800131.

${ }^{[17]}$ D. Brunel, G. Noirbent, F. Dumur, Ferrocene: an unrivaled electroactive building block for the design of push-pull dyes with near-infrared and infrared absorptions, Dyes Pigm. 170 (2019) 107611. https://doi.org/10.1016/j.dyepig.2019.107611

${ }^{[18]}$ P.D. Beer, J.J. Davis, D.A. Drillsma-Milgrom, F. Szemes, Anion recognition and redox sensing amplification by self-assembled monolayers of 1,1'-bis(alkyl-N-amido)ferrocene, Chem. Commun. (2002) 1716-1717. https://doi.org/10.1039/B205340N.

${ }^{[19]}$ M. Cuartero, L. Chai, B. Zhang, R. De Marco, G.A. Crespo, Ferrocene self assembled monolayer as a redox mediator for triggering ion transfer across nanometer-sized membranes, Electrochimica Acta. 315 (2019) 84-93. https://doi.org/10.1016/j.electacta.2019.05.091.

${ }^{[20]}$ L. Yuan, R. Breuer, L. Jiang, M. Schmittel, C.A. Nijhuis, A Molecular Diode with a Statistically Robust Rectification Ratio of Three Orders of Magnitude, Nano Lett. 15 (2015) 5506-5512. https://doi.org/10.1021/acs.nanolett.5b02014.

${ }^{[21]}$ C.A. Nijhuis, W.F. Reus, J.R. Barber, M.D. Dickey, G.M. Whitesides, Charge Transport and Rectification in Arrays of SAM-Based Tunneling Junctions, Nano Lett. $10 \quad$ (2010) 3611-3619. https://doi.org/10.1021/n1101918m.

${ }^{[22]}$ L. Yuan, N. Nerngchamnong, L. Cao, H. Hamoudi, E. del Barco, M. Roemer, R.K. Sriramula, D. Thompson, C.A. Nijhuis, Controlling the direction of rectification in a molecular diode, Nature Communications. 6 (2015) 6324. https://doi.org/10.1038/ncomms7324. 
${ }^{[23]}$ N.K. Devaraj, R.A. Decreau, W. Ebina, J.P. Collman, C.E.D. Chidsey, Rate of Interfacial Electron Transfer through the 1,2,3-Triazole Linkage, J. Phys. Chem. B. 110 (2006) 15955-15962. https://doi.org/10.1021/jp057416p.

${ }^{[24]}$ R. Chelmowski, D. Käfer, S.D. Köster, T. Klasen, T. Winkler, A. Terfort, N. Metzler-Nolte, C. Wöll, Postformation Modification of SAMs: Using Click Chemistry to Functionalize Organic Surfaces, Langmuir. 25 (2009) 11480-11485. https://doi.org/10.1021/la9012813.

${ }^{[25]}$ J.P. Collman, N.K. Devaraj, T.P.A. Eberspacher, C.E.D. Chidsey, Mixed Azide-Terminated Monolayers: A Platform for Modifying Electrode Surfaces, Langmuir. 22 (2006) 2457-2464. https://doi.org/10.1021/la052947q.

${ }^{[26]}$ D. Toulemon, B.P. Pichon, X. Cattoën, M.W.C. Man, S. Begin-Colin, 2D assembly of non-interacting magnetic iron oxide nanoparticles via "click" chemistry, Chem. Commun. 47 (2011) 11954-11956. https://doi.org/10.1039/C1CC14661K.

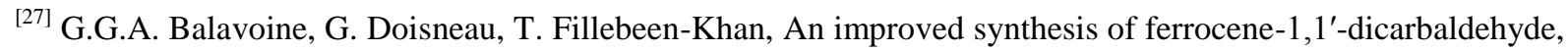
Journal of Organometallic Chemistry. 412 (1991) 381-382. https://doi.org/10.1016/0022-328X(91)86082-2.

${ }^{[28]}$ Z. Zeng, A.A.J. Torriero, M.J. Belousoff, A.M. Bond, L. Spiccia, Synthesis, X-ray Structure of Ferrocene Bearing Bis(Zn-cyclen) Complexes and the Selective Electrochemical Sensing of TpT, Chemistry - A European Journal. 15 (2009) 10988-10996. https://doi.org/10.1002/chem.200901639.

[29] M.C. Martos-Maldonado, M.B. Thygesen, K.J. Jensen, A. Vargas-Berenguel, Gold-Ferrocene GlycoNanoparticles for High-Sensitivity Electrochemical Detection of Carbohydrate-Lectin Interactions, European Journal of Organic Chemistry. 2013 (2013) 2793-2801. https://doi.org/10.1002/ejoc.201300205.

${ }^{[30]}$ B. Misterkiewicz, R. Dabard, A. Darchen, H. Patin, Méthode générale de synthèse à partir d'alphaferrocénylcarbinols de nouveaux thiols, thiolesters et thioétehrs alpha-ferrocényles, Compte rendus de l'académie des sciences de Paris, 309 (1989) 875-880.

${ }^{[31]}$ X. Liu, Y. Wang, C. Chen, A. Tintaru, Y. Cao, J. Liu, F. Ziarelli, J. Tang, H. Guo, R. Rosas, S. Giorgio, L. Charles, P. Rocchi, L. Peng, A Fluorinated Bola-Amphiphilic Dendrimer for On-Demand Delivery of siRNA, via Specific Response to Reactive Oxygen Species, Advanced Functional Materials. 26 (2016) 8594-8603. https://doi.org/10.1002/adfm.201604192.

${ }^{[32]}$ H. Schottenberger, J. Lukassser, E. Reichel, A.G. Müller, G. Steiner, H. Kopacka, K. Wurst, K.H. Ongania, K. Kirchner, Semimasked 1,1'-diethynylferrocenes: synthetic concepts, preparations, and reactions, Journal of Organometallic Chemistry. 637-639 (2001) 558-576. https://doi.org/10.1016/S0022-328X(01)00975-5.

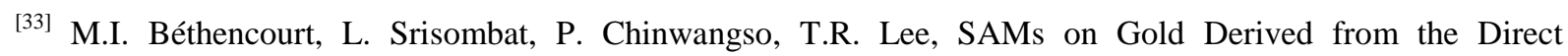
Adsorption of Alkanethioacetates Are Inferior to Those Derived from the Direct Adsorption of Alkanethiols, Langmuir. 25 (2009) 1265-1271. https://doi.org/10.1021/la803179q.

${ }^{[34]}$ R.R. Gagne, C.A. Koval, G.C. Lisensky, Ferrocene as an internal standard for electrochemical measurements, Inorg. Chem. 19 (1980) 2854-2855. https://doi.org/10.1021/ic50211a080.

${ }^{[35]}$ C.E.D. Chidsey, C.R. Bertozzi, T.M. Putvinski, A.M. Mujsce, Coadsorption of ferrocene-terminated and unsubstituted alkanethiols on gold: electroactive self-assembled monolayers, J. Am. Chem. Soc. 112 (1990) 4301-4306. https://doi.org/10.1021/ja00167a028.

${ }^{[36]}$ N.K. Devaraj, J.P. Collman, Copper Catalyzed Azide-Alkyne Cycloadditions on Solid Surfaces: Applications and Future Directions, QSAR \& Combinatorial Science. $26 \quad$ (2007) 1253-1260. https://doi.org/10.1002/qsar.200740121.

${ }^{[37]}$ T. Buffeteau, B. Desbat, J.M. Turlet, Polarization Modulation FT-IR Spectroscopy of Surfaces and UltraThin Films: Experimental Procedure and Quantitative Analysis, Appl Spectrosc. 45 (1991) 380-389. https://doi.org/10.1366/0003702914337308.

${ }^{[38]}$ M.A. Ramin, G. Le Bourdon, N. Daugey, B. Bennetau, L. Vellutini, T. Buffeteau, PM-IRRAS Investigation of Self-Assembled Monolayers Grafted onto SiO2/Au Substrates, Langmuir. 27 (2011) 6076-6084. https://doi.org/10.1021/la2006293. 
${ }^{[39]}$ C.-K. Liang, G.V. Dubacheva, T. Buffeteau, D. Cavagnat, P. Hapiot, B. Fabre, J.H.R. Tucker, D.M. Bassani, Reversible Control over Molecular Recognition in Surface-Bound Photoswitchable Hydrogen-Bonding Receptors: Towards Read-Write-Erase Molecular Printboards, Chemistry - A European Journal. 19 (2013) 12748-12758. https://doi.org/10.1002/chem.201301613.

${ }^{[40]}$ N. Al-Hajj, Y. Mousli, A. Miche, V. Humblot, J. Hunel, K. Heuzé, T. Buffeteau, E. Genin, L. Vellutini, Influence of the grafting process on the orientation and the reactivity of azide-terminated monolayers onto silica surface, Applied Surface Science. 527 (2020) 146778. https://doi.org/10.1016/j.apsusc.2020.146778.

${ }^{[41]}$ G. Socrates, Infrared and Raman characteristic group frequencies : tables and charts, 3rd ed., Chichester : Wiley, 2001. http://lib.ugent.be/catalog/rug01:001212111.

${ }^{[42]}$ M.D. Porter, T.B. Bright, D.L. Allara, C.E.D. Chidsey, Spontaneously organized molecular assemblies. 4. Structural characterization of n-alkyl thiol monolayers on gold by optical ellipsometry, infrared spectroscopy, and electrochemistry, J. Am. Chem. Soc. 109 (1987) 3559-3568. https://doi.org/10.1021/ja00246a011.

${ }^{[43]}$ R.V. Duevel, R.M. Corn, Amide and ester surface attachment reactions for alkanethiol monolayers at gold surfaces as studied by polarization modulation Fourier transform infrared spectroscopy, Anal. Chem. 64 (1992) 337-342. https://doi.org/10.1021/ac00028a003.

${ }^{[44]}$ T.P. Gryaznova, S.A. Katsyuba, V.A. Milyukov, O.G. Sinyashin, DFT study of substitution effect on the geometry, IR spectra, spin state and energetic stability of the ferrocenes and their pentaphospholyl analogues, Journal of Organometallic Chemistry. 695 (2010) 2586-2595. https://doi.org/10.1016/j.jorganchem.2010.08.031.

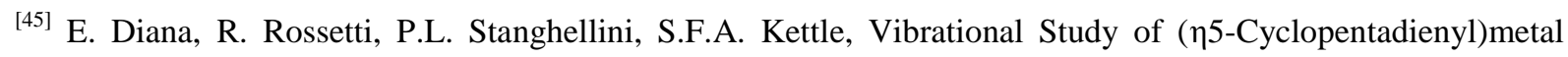
Complexes, Inorg. Chem. 36 (1997) 382-391. https://doi.org/10.1021/ic960545n.

${ }^{[46]}$ S. Ciampi, P.K. Eggers, G. Le Saux, M. James, J.B. Harper, J.J. Gooding, Silicon (100) Electrodes Resistant to Oxidation in Aqueous Solutions: An Unexpected Benefit of Surface Acetylene Moieties, Langmuir. 25 (2009) 2530-2539. https://doi.org/10.1021/la803710d.

${ }^{[47]}$ S. Ciampi, T. Böcking, K.A. Kilian, M. James, J.B. Harper, J.J. Gooding, Functionalization of AcetyleneTerminated Monolayers on Si(100) Surfaces: A Click Chemistry Approach, Langmuir. 23 (2007) 9320-9329. https://doi.org/10.1021/la701035g.

${ }^{[48]}$ M.-C. Bourg, A. Badia, R.B. Lennox, Gold-Sulfur Bonding in 2D and 3D Self-Assembled Monolayers: XPS Characterization, J. Phys. Chem. B. 104 (2000) 6562-6567. https://doi.org/10.1021/jp9935337.

${ }^{[49]}$ A.G. Marrani, E.A. Dalchiele, R. Zanoni, F. Decker, F. Cattaruzza, D. Bonifazi, M. Prato, Functionalization of $\mathrm{Si}(100)$ with ferrocene derivatives via "click" chemistry, Electrochimica Acta. 53 (2008) 3903-3909. https://doi.org/10.1016/j.electacta.2007.10.051.

${ }^{[50]}$ H. Liu, F. Duclairoir, B. Fleury, L. Dubois, Y. Chenavier, J.-C. Marchon, Porphyrin anchoring on Si(100) using a $\beta$-pyrrolic position, Dalton Trans. (2009) 3793-3799. https://doi.org/10.1039/B901309A.

${ }^{[51]}$ C.M. Woodbridge, D.L. Pugmire, R.C. Johnson, N.M. Boag, M.A. Langell, HREELS and XPS Studies of Ferrocene on $\operatorname{Ag}(100)$, J. Phys. Chem. B. 104 (2000) 3085-3093. https://doi.org/10.1021/jp993235+.

${ }^{[52]}$ XPS Interpretation of Oxygen, (n.d.). https://xpssimplified.com/elements/oxygen.php (accessed March 12, 2021).

${ }^{[53]}$ V.P. Hitaishi, R. Clément, L. Quattrocchi, P. Parent, D. Duché, L. Zuily, M. Ilbert, E. Lojou, I. Mazurenko, Interplay between Orientation at Electrodes and Copper Activation of Thermus thermophilus Laccase for O2 Reduction, J. Am. Chem. Soc. 142 (2020) 1394-1405. https://doi.org/10.1021/jacs.9b11147.

${ }^{[54]}$ V.P. Hitaishi, I. Mazurenko, M. Harb, R. Clément, M. Taris, S. Castano, D. Duché, S. Lecomte, M. Ilbert, A. de Poulpiquet, E. Lojou, Electrostatic-Driven Activity, Loading, Dynamics, and Stability of a Redox Enzyme on Functionalized-Gold Electrodes for Bioelectrocatalysis, ACS Catal. $8 \quad$ (2018) 12004-12014. https://doi.org/10.1021/acscatal.8b03443. 
${ }^{[55]}$ A. Shakiba, A.C. Jamison, T.R. Lee, Poly(1-lysine) Interfaces via Dual Click Reactions on Surface-Bound Custom-Designed Dithiol Adsorbates, Langmuir. $\quad 31 \quad$ 6154-6163. https://doi.org/10.1021/acs.langmuir.5b00877.

${ }^{[56]}$ J.M. Spruell, B.A. Sheriff, D.I. Rozkiewicz, W.R. Dichtel, R.D. Rohde, D.N. Reinhoudt, J.F. Stoddart, J.R. Heath, Heterogeneous Catalysis through Microcontact Printing, Angewandte Chemie International Edition. 47 (2008) 9927-9932. https://doi.org/10.1002/anie.200803480.

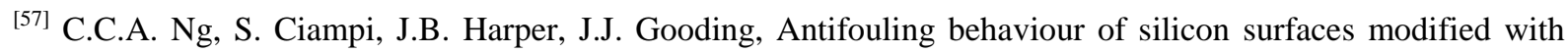
self-assembled monolayers containing both ethylene glycol and charged moieties, Surface Science. 604 (2010) 1388-1394. https://doi.org/10.1016/j.susc.2010.04.025.

${ }^{[58]}$ C.M. Yam, S.S.Y. Tong, A.K. Kakkar, Simple Acid-Base Hydrolytic Chemistry Approach to Molecular Self-Assembly: Thin Films of Long Chain Alcohols Terminated with Alkyl, Phenyl, and Acetylene Groups on Inorganic Oxides Surfaces, Langmuir. 14 (1998) 6941-6947. https://doi.org/10.1021/la9806909.

${ }^{[59]}$ C.D. Bain, E.B. Troughton, Y.T. Tao, J. Evall, G.M. Whitesides, R.G. Nuzzo, Formation of monolayer films by the spontaneous assembly of organic thiols from solution onto gold, J. Am. Chem. Soc. 111 (1989) $321-335$. https://doi.org/10.1021/ja00183a049.

${ }^{[60]}$ Y.-S. Shon, Colorado Ramon, C.T. Williams, C.D. Bain, T.R. Lee, Low-Density Self-Assembled Monolayers on Gold Derived from Chelating 2-Monoalkylpropane-1,3-dithiols, Langmuir. 16 (2000) 541-548. https://doi.org/10.1021/la9816981.

${ }^{[61]}$ M.M. Thuo, W.F. Reus, C.A. Nijhuis, J.R. Barber, C. Kim, M.D. Schulz, G.M. Whitesides, Odd-Even Effects in Charge Transport across Self-Assembled Monolayers, J. Am. Chem. Soc. 133 (2011) 2962-2975. https://doi.org/10.1021/ja1090436.

${ }^{[62]}$ T. Buffeteau, B. Desbat, D. Blaudez, J.-M. Turlet Calibration Procedure to Derive IRRAS Spectra from PMIRRAS Spectra, Appl. Spectrosc. 54 (2000) 1646-1650. https://doi.org/10.1366/0003702001948673.

${ }^{[63]}$ A.D. Rakić, A.B. Djurišić, J.M. Elazar, M.L. Majewski, Optical properties of metallic films for verticalcavity optoelectronic devices, Appl. Opt. 37 (1998) 5271-5283. https://doi.org/10.1364/AO.37.005271. 